1

17

9

\title{
Validation and invalidation of SARS-CoV-2 main protease inhibitors using the Flip-GFP and Protease-Glo luciferase assays
} Chunlong Ma, ${ }^{a}$ Haozhou Tan, ${ }^{a}$ Juliana Choza, ${ }^{a}$ Yuying Wang, ${ }^{a}$ and Jun Wang, $,{ }^{a},{ }^{*}$

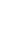

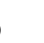

aDepartment of Pharmacology and Toxicology, College of Pharmacy, The University of Arizona, Tucson, USA, 85721.

*Address correspondence to Jun Wang, junwang@pharmacy.arizona.edu

1

Running title: Validation/invalidation of SARS-CoV-2 $\mathrm{M}^{\text {pro inhibitors }}$

3

4

15

6

8

0

1

2




\section{Graphical abstract}

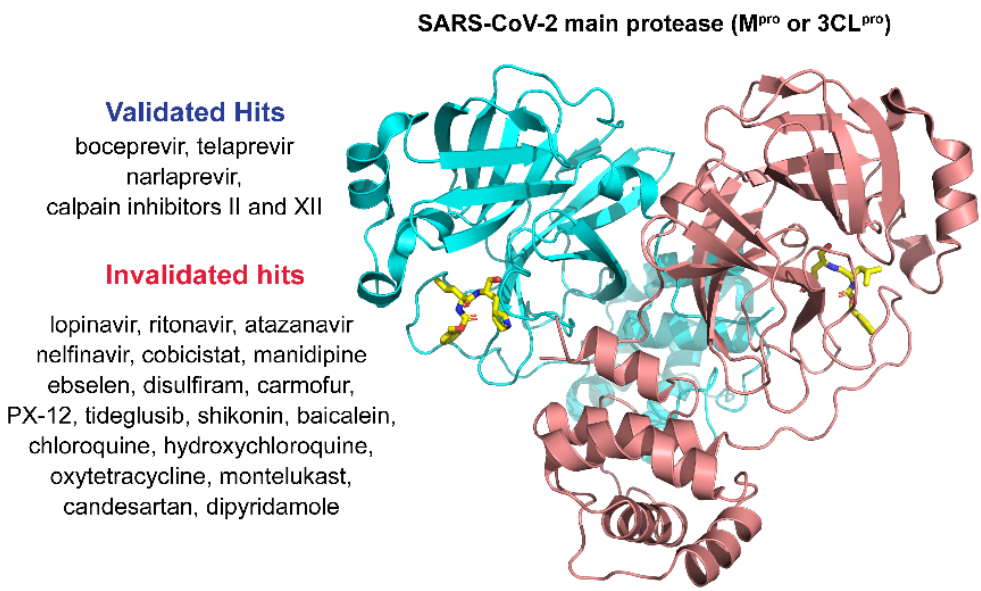

27 Flip-GFP and Protease-Glo luciferase assays, coupled with the FRET and thermal shift 


\section{Abstract}

41 SARS-CoV-2 main protease $\left(\mathrm{M}^{\mathrm{pro}}\right)$ is one of the most extensive exploited drug targets

42 for COVID-19. Structurally disparate compounds have been reported as Mpro inhibitors, 43 raising the question of their target specificity. To elucidate the target specificity and the 44 cellular target engagement of the claimed $M^{\text {pro }}$ inhibitors, we systematically characterize their mechanism of action using the cell-free FRET assay, the thermal shift-binding assay, the cell lysate Protease-Glo luciferase assay, and the cell-based Flip-GFP assay. Collectively, our results have shown that majority of the $\mathrm{M}^{\text {pro }}$ inhibitors identified from drug repurposing including ebselen, carmofur, disulfiram, and shikonin are promiscuous cysteine inhibitors that are not specific to $\mathrm{M}^{\text {pro, }}$, while chloroquine, oxytetracycline, montelukast, candesartan, and dipyridamole do not inhibit $\mathrm{M}^{\text {pro }}$ in any of

51 the assays tested. Overall, our study highlights the need of stringent hit validation at the 52 early stage of drug discovery.

Keywords: SARS-CoV-2, antiviral, main protease, ebselen, carmofur, Flip-GFP assay, 


\section{INTRODUCTION}

SARS-CoV-2 is the causative agent for COVID-19, which infected 221 million people and led to 4.44 million deaths as of August 23, 2021. SARS-CoV-2 is the third coronavirus that causes epidemics and pandemics in human. SARS-CoV-2, along with SARS-CoV and MERS-CoV, belong to the $\beta$ genera of the coronaviridae family ${ }^{1}$. SARSCoV-2 encodes two viral cysteine proteases, the main protease $\left(\mathrm{M}^{\text {pro }}\right)$ and the papainlike protease $\left(\mathrm{PL}^{\mathrm{pro}}\right)$, that mediate the cleavage of viral polyproteins pp1a and pp1ab during viral replication ${ }^{2,3}$. $\mathrm{M}^{\text {pro }}$ cleaves at more than 11 sites at the viral polyproteins and has a high substrate preference for glutamine at the P1 site ${ }^{4}$. In addition, the $\mathrm{M}^{\text {pro }}$ is highly conserved among coronaviruses that infect human including SARS-CoV-2, SARS-CoV, MERS-CoV, HCoV-OC43, HCoV-NL63, HCoV-229E, and HCoV-HKU1. For these reasons, $\mathrm{M}^{\text {pro }}$ becomes a high-profile drug target for the development of broadspectrum antivirals. Structurally disparate compounds including FDA-approved drugs and bioactive compounds have been reported as $\mathrm{M}^{\text {pro }}$ inhibitors ${ }^{5-7}$, several of which also have antiviral activity against SARS-CoV-28-10.

FRET assay is the gold standard assay for protease and is typically used as a primary assay for the screening of $\mathrm{M}^{\text {pro }}$ inhibitors. However, the FRET assay conditions used by different groups vary significantly in terms of the protein and substrate concentrations, $\mathrm{pH}$, reducing reagent, and detergent. Reducing reagent is typically added in the assay buffer to prevent the non-specific oxidation or alkylation of the catalytic C145 in $\mathrm{M}^{\text {pro }}$. Nonetheless, many studies do not include reducing reagents in the FRET assay buffer, leading to debatable results ${ }^{8}$. Regardless of the assay condition, FRET assay is a cell free biochemical assay, which does not mimic the cellular environment; therefore, the results cannot be used to accurately predict the cellular activity of the $\mathrm{M}^{\text {pro }}$ inhibitor or the antiviral activity. Moreover, one limiting factor

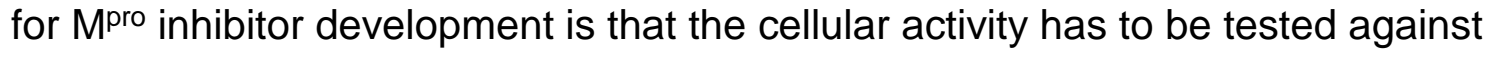
infectious SARS-CoV-2 in BSL-3 facility, which is inaccessible to many researchers. For these reasons, there is a pressing need of secondary $\mathrm{M}^{\text {pro }}$ target-specific assays that can closely mimic the cellular environment and be used to rule out false positives. 
In this study, we report our findings of validating or invalidating the literature

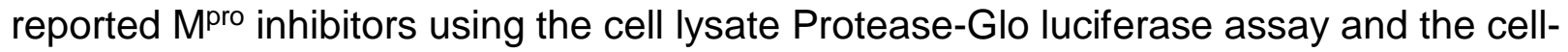
based Flip-GFP assay, in conjunction to the cell-free FRET assay and thermal shiftbinding assay. The purpose is to elucidate their target specificity and cellular target engagement. The Protease-Glo luciferase assay was developed in this study, and the Flip-GFP assay was recently developed by us and others ${ }^{11-14}$. Our results have collectively shown that majority of the $\mathrm{M}^{\text {pro }}$ inhibitors identified from drug repurposing screening including ebselen, carmofur, disulfiram, and shikonin are promiscuous cysteine inhibitors that are not specific to $\mathrm{M}^{\text {pro }}$, while chloroquine, oxytetracycline, montelukast, candesartan, and dipyridamole do not inhibit $\mathrm{M}^{\text {pro }}$ in any of the assays tested. The results presented herein highlight the pressing need of stringent hit validation at the early stage of drug discovery to minimize the catastrophic failure in the following translational development.

\section{RESULTS AND DISCUSSION}

\subsection{Assay validation using GC-376 and rupintrivir as positive and negative controls}

The advantages and disadvantages of the cell lysate Protease-Glo luciferase assay and the cell-based Flip-GFP assay compared to the cell free FRET assay are listed in Table 1. To minimize the bias from a particular assay, we apply all these three functional assays together with the thermal shift-binding assay for the hit validation.

115 Table 1. Advantages and disadvantages of the three functional assays used in this study.

\begin{tabular}{|c|c|c|}
\hline & Advantages & Disadvantages \\
\hline FRET assay & - High-throughput & $\begin{array}{l}\text { - Compounds that quench the fluorophore will show } \\
\text { up as false positives } \\
\text { - Assay interference from fluorescent compounds, } \\
\text { detergents, and aggregators. } \\
\text { - Cannot be used to predict the cellular antiviral } \\
\quad \text { activity } \\
\text { - No standard condition among scientific community }\end{array}$ \\
\hline Flip-GFP assay & $\begin{array}{l}\text { - Can rule out compounds that are } \\
\text { cytotoxic, membrane impermeable, or } \\
\text { substrates of drug efflux pump } \\
\text { - A close mimetic of virus-infected cell } \\
\text { - Can be used to predict the cellular } \\
\text { antiviral activity } \\
\text { - Reveals cellular target engagement } \\
\end{array}$ & $\begin{array}{l}\text { - The assay takes } 48 \mathrm{hrs} \text {, thus it cannot be used for } \\
\text { cytotoxic compounds } \\
\text { • Interference from fluorescent compounds }\end{array}$ \\
\hline $\begin{array}{l}\text { Protease-Glo luciferase } \\
\text { assay }\end{array}$ & $\begin{array}{l}\bullet \text { High-throughput } \\
\text { - Reveals cellular target engagement } \\
\text { - Can be used to test cytotoxic } \\
\text { compounds }\end{array}$ & $\begin{array}{l}\text { - Cannot be used to predict the cellular antiviral } \\
\text { activity }\end{array}$ \\
\hline
\end{tabular}


In the cell-based Flip-GFP assay, the cells were transfected with two plasmids, one expresses the SARS-CoV-2 M ${ }^{\text {pro }}$, and another expresses the GFP reporter ${ }^{15}$. The GFP reporter plasmid expresses three proteins including the GFP $\beta 10-\beta 11$ fragment flanked by the K5/E5 coiled coil, the GFP $\beta$ 1-9 template, and the mCherry (Fig. 1A). mCherry serves as an internal control for the normalization of the expression level or the quantification of compound toxicity. In the assay design, $\beta 10$ and $\beta 11$ were conformationally constrained in the parallel position by the heterodimerizing K5/E5 coiled coil with a $M^{\text {pro }}$ cleavage sequence (AVLQ $\left.\downarrow S G F R\right)$. Upon cleavage of the linker by $M^{\text {pro }}, \beta 10$ and $\beta 11$ become antiparallel and can associate with the $\beta 1-9$ template, resulting in the restoration of the GFP signal. In principle, the ratio of GFP/mCherry fluorescence is proportional to the enzymatic activity of $\mathrm{M}^{\text {pro }}$. The Flip-GFP $\mathrm{M}^{\text {pro }}$ assay has been used by several groups to characterize the cellular activity of $\mathrm{M}^{\text {pro }}$ inhibitors ${ }^{11,13,14}$.

In the cell lysate Protease-Glo luciferase assay, the cells were transfected with pGloSensor-30F luciferase reporter (Fig. 1B) ${ }^{16}$. The pGloSensor-30F luciferase reporter plasmid expresses two proteins, the inactive, circularly permuted firefly luciferase (FFluc) and the active Renilla luciferase (Rluc). Renilla luciferase was included as an internal control to normalize the protein expression level. The firefly luciferase was split into two fragments, the FF 4-354 and FF 358-544. The SARS-CoV-2 $\mathrm{M}^{\text {pro }}$ substrate cleavage sequence (AVLQ/SGFR) was inserted in between the two fragments. Before protease cleavage, the pGloSensor-30F reporter comprises an inactive circularly permuted firefly luciferase. The cells were lysed at $24 \mathrm{~h}$ post transfection, and $\mathrm{M}^{\text {pro }}$ and the luciferase substrates were added to initiate the reaction. Upon protease cleavage, a conformational change in firefly luciferase leads to drastically increases luminescence. In principle, the ratio of FFluc/Rluc luminescence is proportional to the enzymatic activity of $\mathrm{M}^{\text {pro }}$.

To calibrate the Flip-GFP and split-luciferase assays, we chose GC-376 and rupintrivir as positive and negative controls, respectively. The $\mathrm{IC}_{50}$ values for GC-376 in the Flip-GFP and split-luciferase assays were $2.35 \mu \mathrm{M}$ and $0.023 \mu \mathrm{M}$, respectively (Fig. 1C, D, and F). The IC 50 value in the Flip-GFP assay is similar to its antiviral activity (Table 2), suggesting the Flip-GFP can be used to predict the cellular antiviral activity. In contrast, rupintrivir showed no activity in either the Flip-GFP (IC $50>50 \mu \mathrm{M})$ (Fig. 1C second row and 1E) or the Protease-Glo luciferase

146 assay $\left(\mathrm{IC}_{50}>100 \mu \mathrm{M}\right)$ (Fig. 1G), which agrees with the lack of inhibition from the FRET assay

$147 \quad\left(\mathrm{IC}_{50}>20 \mu \mathrm{M}\right)$. Nonetheless, rupintrivir was reported to inhibit SARS-CoV-2 replication with an

$148 \mathrm{EC}_{50}$ of $1.87 \mu \mathrm{M}$ using the nanoluciferase SARS-CoV-2 reporter virus (SARS-CoV-2-Nluc) in 
151 luciferase assays are validated as target-specific assays for SARS-CoV-2 Mpro.

A
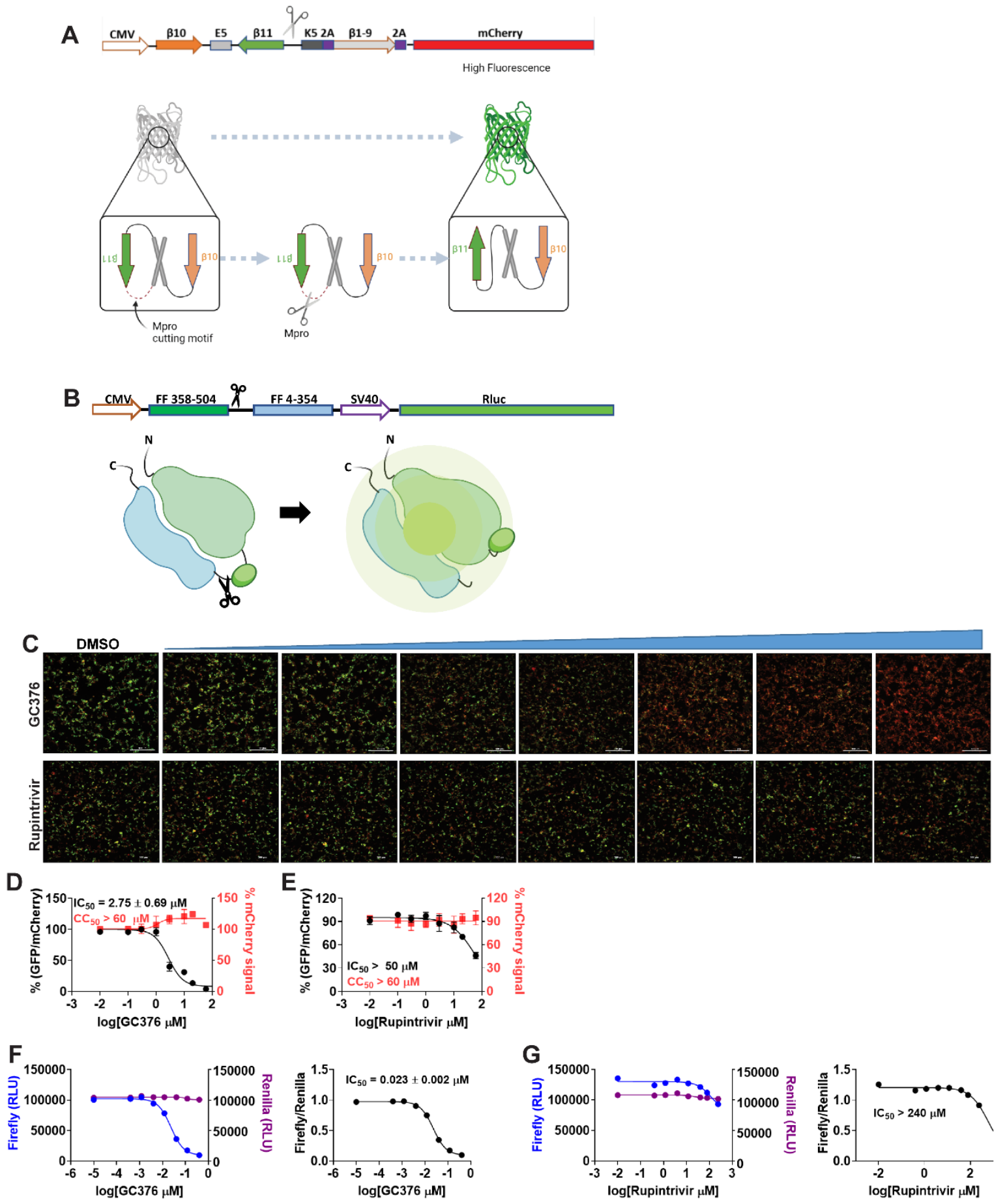
154 Figure 1. Principles for the Flip-GFP and Protease-Glo luciferase assays and assay validation

155 with control compounds. (A) Assay principle for the Flip-GFP assay. Diagram of the Flip-GFP

$156 \mathrm{M}^{\text {pro }}$ reporter plasmid is shown. (B) Assay principle for the Protease-Glo luciferase assay.

157 Diagram of pGlo-M $\mathrm{M}^{\text {pro }}$ luciferase reporter in the pGloSensor-30F vector is shown. (C)

158 Representative images from the FlipGFP-M ${ }^{\text {pro }}$ assay. Dose-dependent decrease of GFP signal 159 was observed with the increasing concentration of GC-376 (positive control); almost no GFP

160 signal change was observed with the increasing concentration of Rupintrivir (negative control).

161 (D-E) Dose-response curve of the ratio of GFP/mCherry fluorescence with GC-376 and

162 rupintrivir; mCherry signal alone was used to normalize protein expression level or calculate

163 compound cytotoxicity. (F-G) Protease-Glo luciferase assay results of GC-376 and rupintrivir.

164 Left column showed Firefly and Renilla luminescence signals in the presences of increasing

165 concentrations of GC-376 and rupintrivir; Right column showed dose-response curve plots of

166 the ratio of FFluc/Rluc luminescence.

167 Table 2. Summary of results.

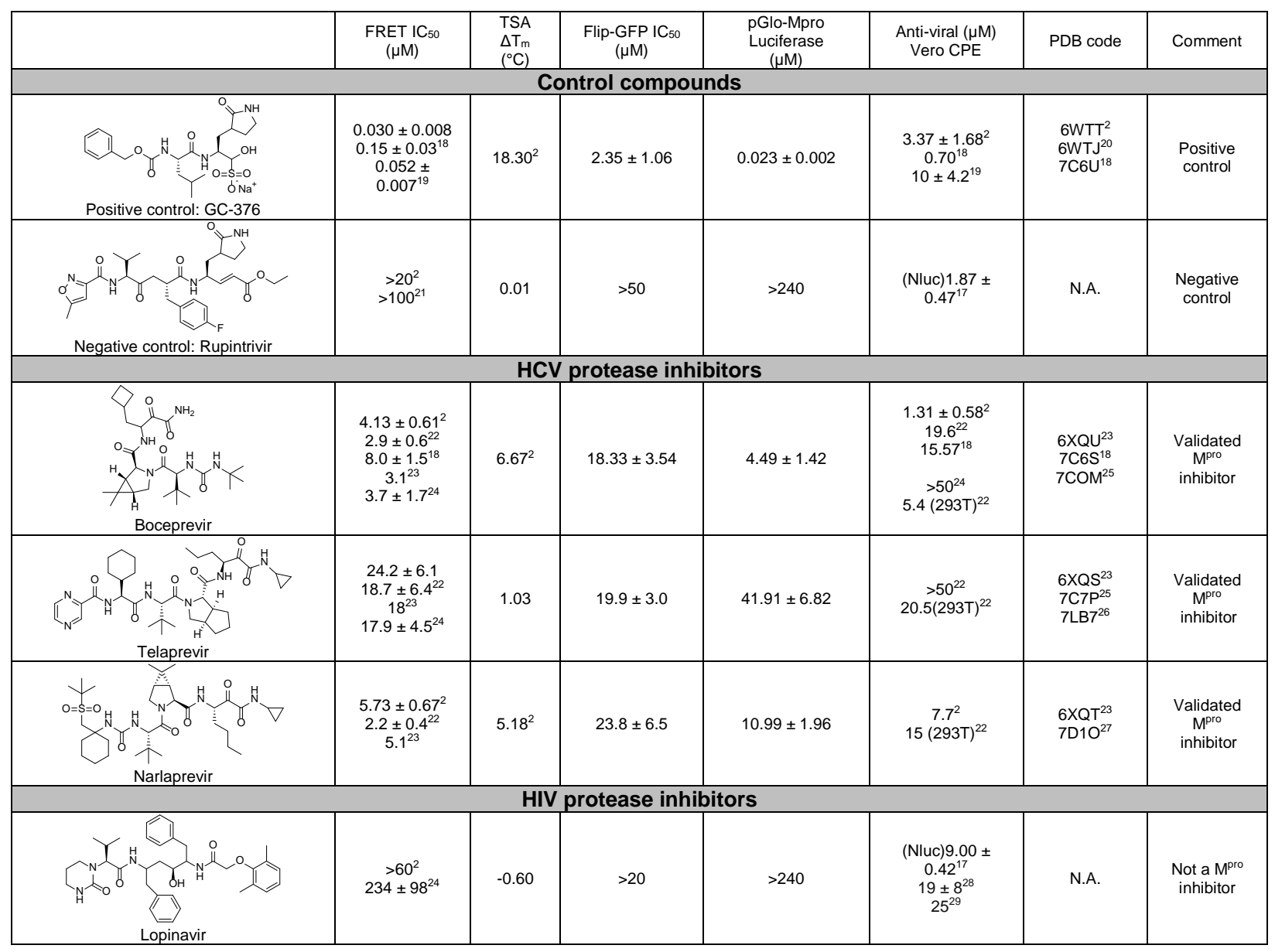


bioRxiv preprint doi: https://doi.org/10.1101/2021.08.28.458041; this version posted August 30, 2021. The copyright holder for this preprint (which was not certified by peer review) is the author/funder, who has granted bioRxiv a license to display the preprint in perpetuity. It is made available under aCC-BY 4.0 International license.

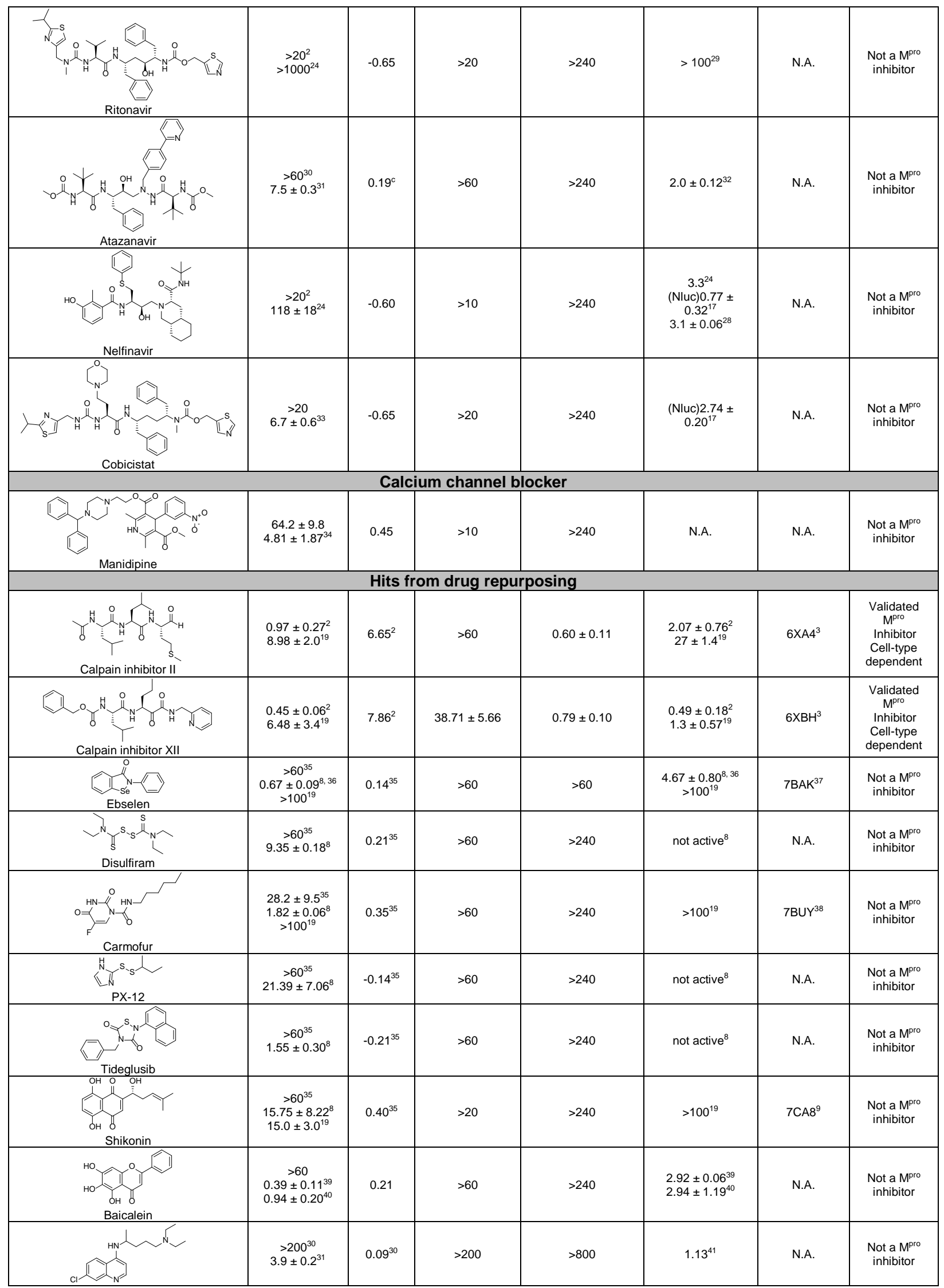




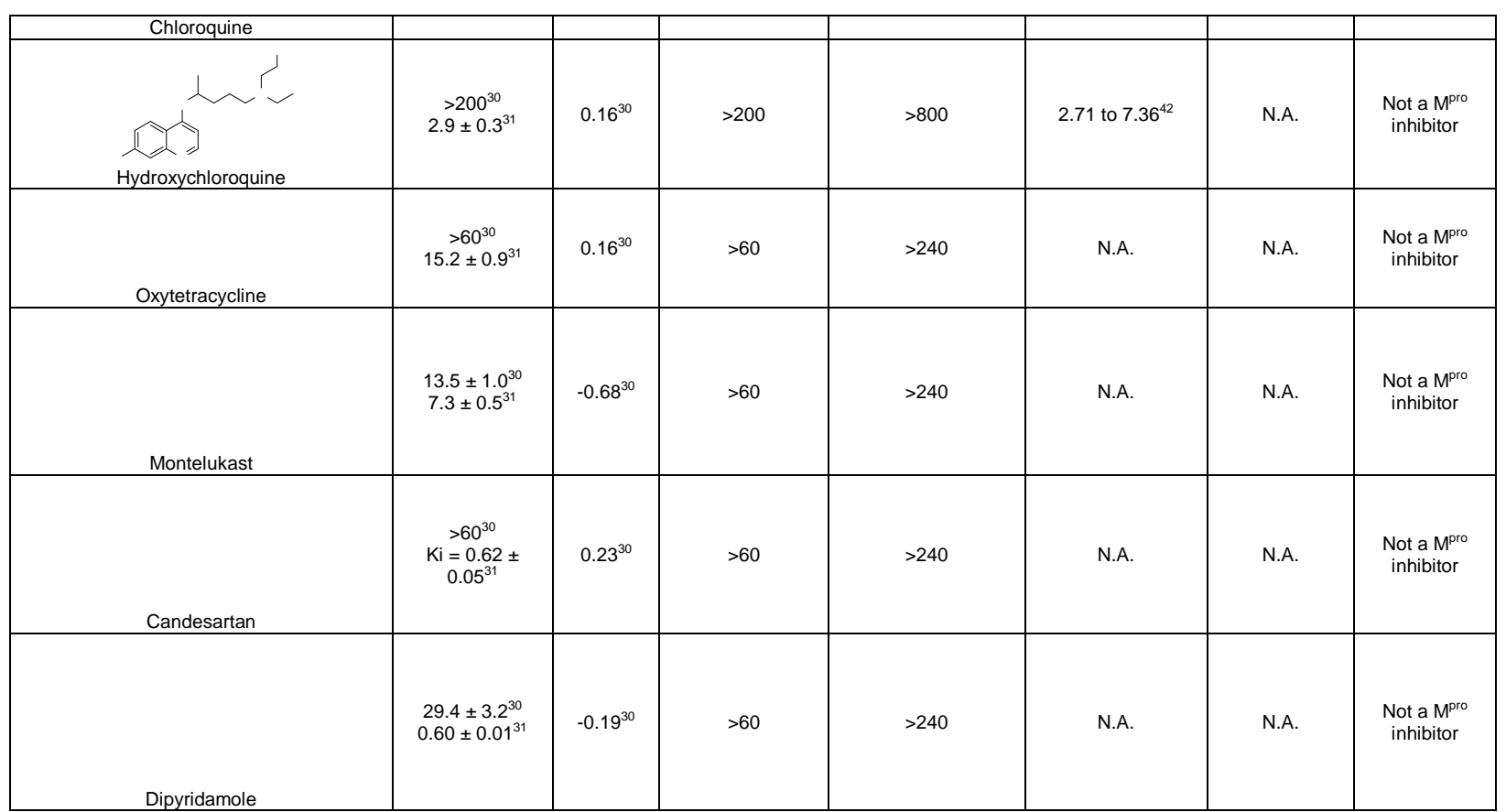

N.A. = not available

\subsection{HCV protease inhibitors}

172 inhibitors ${ }^{2}, 22,43$. From screening a focused protease library using the FRET assay, we

173 discovered simeprevir, boceprevir, and narlaprevir as SARS-CoV-2 Mpro inhibitors with IC $_{50}$

174 values of $13.74,4.13$, and $5.73 \mu \mathrm{M}$, respectively, while telaprevir was less active (31\% inhibition

175 at $20 \mu \mathrm{M})^{2}$. The binding of boceprevir to $\mathrm{M}^{\text {pro }}$ was characterized by thermal shift assay and

176 native mass spectrometry. Boceprevir inhibited SARS-CoV-2 viral replication in Vero E6 cells

177 with $\mathrm{EC}_{50}$ values of 1.31 and $1.95 \mu \mathrm{M}$ in the primary CPE and secondary viral yield reduction

178 assays, respectively (Table 2). In parallel, Fu et al also reported boceprevir as a SARS-CoV-2

$179 \mathrm{M}^{\text {pro }}$ inhibitor with an enzymatic inhibition $\mathrm{IC}_{50}$ of $8.0 \mu \mathrm{M}$ and an antiviral $\mathrm{EC}_{50}$ of $15.57 \mu \mathrm{M}^{18}$. The

180 X-ray crystal structure of $\mathrm{M}^{\text {pro }}$ with boceprevir was solved, revealing a covalent modification of

181 the $\mathrm{C} 145$ thiol by the ketoamide (PDBs: 6XQU ${ }^{43}, 7 \mathrm{C}^{18} \mathrm{~S}^{18}, 7 \mathrm{COM}^{25}$ ).

In the current study, we found that boceprevir showed moderate inhibition in the cellular

183 Flip-GFP M ${ }^{\text {pro }}$ assay with an $\mathrm{IC}_{50}$ of $18.33 \mu \mathrm{M}$ (Fig. 2A and B), a more than 4-fold increase

184 compared to the $I_{50}$ in the FRET assay $(4.13 \mu \mathrm{M})$. The $\mathrm{IC}_{50}$ value of boceprevir in the cell

185 lysate Protease-Glo luciferase assay was $4.49 \mu \mathrm{M}$ (Fig. 2E). In comparison, telaprevir and

186 narlaprevir showed weaker inhibition than boceprevir in both the Flip-GFP and Protease-Glo

187 luciferase assays (Fig. 2A, C, D, F, and G), which is consistent with their weaker potency in the 
FRET assay (Table 2). Overall, boceprevir, telaprevir, and narlaprevir have been validated as SARS-CoV-2 $\mathrm{M}^{\text {pro }}$ inhibitors in both the cellular Flip-GFP assay and the cell lysate Protease-Glo luciferase assay. Therefore, the antiviral activity of these three compounds against SARS-CoV2 are likely due to $\mathrm{M}^{\text {pro }}$ inhibition. Although the inhibition of $\mathrm{M}^{\text {pro }}$ by boceprevir is relatively weak compared to GC-376, several highly potent $\mathrm{M}^{\text {pro }}$ inhibitors were subsequently designed as hybrids of boceprevir and GC-376 including the Pfizer oral drug candidate PF-07321332, which contain the dimethylcyclopropylproline at the P2 substitution ${ }^{11,25,44 .}$
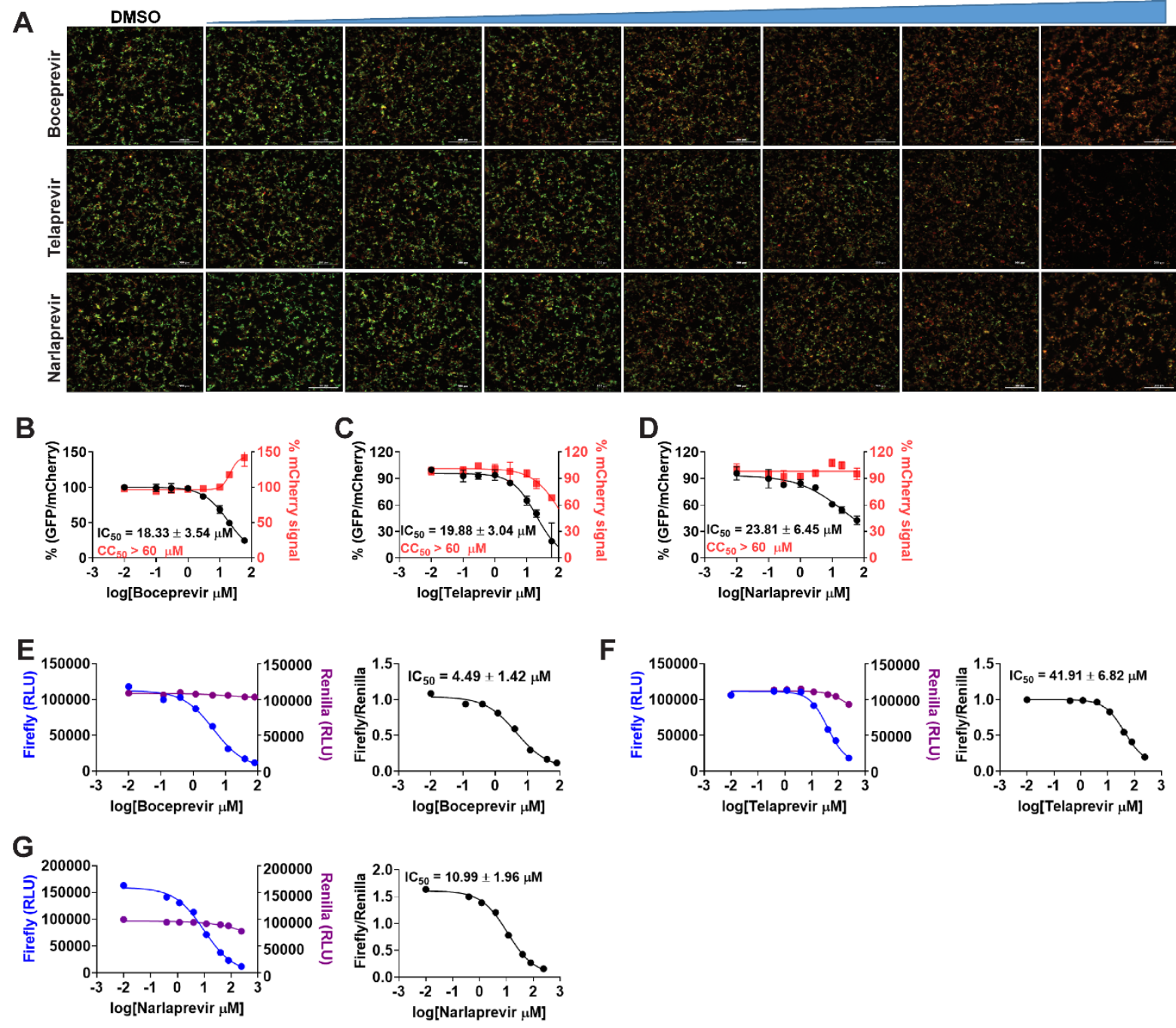

195

Figure 2: Validation/invalidation of hepatitis C virus NS3/4A protease inhibitors boceprevir, telaprevir, and narlaprevir as SARS CoV-2 Mpro inhibitors using the Flip-GFP assay and Protease-Glo luciferase assay. (A) Representative images from the Flip-GFP-Mpro assay. Dosedependent decrease of GFP signal was observed with the increasing concentration of boceprevir, telaprevir or narlaprevir. (B-D) Dose-response curve of the GFP and mCherry 
201

202

203

204

205

206

207

208

209

210

211

212

213

214

215

216

217

218

219

220

221

222

223

224

225

226

227

228

229

230

231

232

fluorescent signals for boceprevir (B), telaprevir (C) or narlaprevir (D); mCherry signal alone was used to normalize protein expression level or calculate compound toxicity. (E-G) Protease-Glo luciferase assay results of boceprevir (E), telaprevir (F) or narlaprevir (G). Left column showed Firefly and Renilla luminescence signals in the presences of increasing concentrations of boceprevir, telaprevir or narlaprevir; Right column showed dose-response curve plots of the ratio of FFluc/Rlu luminescence. Renilla luminescence signal alone was used to normalize protein expression level.

\subsection{HIV protease inhibitors}

HIV protease inhibitors, especially Kaletra, have been hotly pursued as potential COVID-19 treatment at the beginning of the pandemic. Kaletra was first tested in clinical trial during the SARS-CoV outbreak in 2003 and showed somewhat promising results based on the limited data ${ }^{45}$. However, a double-blinded, randomized trial concluded that Kaletra was not effective in treating severe COVID-1946, 47. In SARS-CoV-2 infection ferret models, Kaletra showed marginal effect in reducing clinical symptoms, while had no effect on virus titers ${ }^{48}$.

Keletra is a combination of lopinavir and ritonavir. Lopinavir is a HIV protease inhibitor, and ritonavir is used as a booster. Ritonavir does not inhibit the HIV protease and it is a cytochrome P450-3A4 inhibitor ${ }^{49}$. When used in combination, ritonavir can enhance other protease inhibitors by preventing or slowing down the metabolism. In cell culture, lopinavir was reported to inhibit the nanoluciferase SARS-CoV-2 reporter virus with an $\mathrm{EC}_{50}$ of $9 \mu \mathrm{M}^{17}$. In two other studies, lopinavir showed moderate antiviral activity against SARS-CoV-2 activity with EC $_{50}$ values of $19 \pm 8 \mu \mathrm{M}^{28}$ and $25 \mu \mathrm{M}^{29}$. As such, it was assumed that lopinavir inhibited SARS-CoV-2 through inhibiting the $\mathrm{M}^{\text {pro }}$. However, lopinavir showed no activity against SARS-CoV-2 $\mathrm{M}^{\text {pro }}$ in the FRET assay from our previous study $\left(\mathrm{IC}_{50}>60 \mu \mathrm{M}\right)^{2}$. Wong et al also showed that lopinavir was a weak inhibitor against SARS-CoV $\mathrm{M}^{\text {pro }}$ with an $\mathrm{IC}_{50}$ of $50 \mu \mathrm{M}^{50}$. In the current study, we further confirmed the lack of binding of lopinavir to SARS-CoV-2 $\mathrm{M}^{\text {pro }}$ in the thermal shift assay $\left(\Delta \mathrm{T}_{\mathrm{m}}=\right.$ $0.60^{\circ} \mathrm{C}$ ) (Table 2). The result from the Flip-GFP assay was not conclusive as lopinavir was cytotoxic. Lopinavir was not active in the Protease-Glo luciferase assay. Taken together, lopinavir is not a $\mathrm{M}^{\text {pro }}$ inhibitor.

We also tested additional HIV antivirals including ritonavir, atazanavir, nelfinavir, and cobicistat. Atazanavir and nelfinavir were reported as a potent SARS-CoV-2 antiviral with EC $_{50}$ values of $2.0 \pm 0.12^{32}$ and $0.77 \mu \mathrm{M}^{17}$ using the infectious SARS-CoV-2 and the nanoluciferase 
233 reporter virus (SARS-CoV-2-Nluc), respectively. A drug repurposing screening similar identified

234 nelfinavir as a SARS-CoV-2 antiviral with an $\mathrm{IC}_{50}$ of $3.3 \mu \mathrm{M}^{24}$. Sharma et al showed that

235 cobicistat inhibited $\mathrm{M}^{\text {pro }}$ with an $\mathrm{IC}_{50}$ of $6.7 \mu \mathrm{M}$ in the FRET assay ${ }^{33}$. Cobicistat was also reported

236 to have antiviral activity against SARS-CoV-2 with an $\mathrm{EC}_{50}$ of $2.74 \pm 0.20 \mu \mathrm{M}$ using the SARS-

237 CoV-2-Nluc reporter virus ${ }^{17}$. However, our FRET assay showed that ritonavir, nelfinavir, and

238 cobicistat did not inhibit $\mathrm{M}^{\text {pro }}$ in the FRET assay $\left(\mathrm{IC}_{50}>20 \mu \mathrm{M}\right)$, which was further confirmed by

239 the lack of binding to $\mathrm{M}^{\text {pro }}$ in the thermal shift assay (Table 2). The results from the Flip-GFP

240 assay were not conclusive due to compound cytotoxicity. None of the compounds showed

241 inhibition in the Protease-Glo luciferase assay.

242 Collectively, our results have shown that the HIV protease inhibitors including lopinavir,

243 ritonavir, atazanavir, nelfinavir, and cobicistat are not $\mathrm{M}^{\text {pro }}$ inhibitors. Nonetheless, given the

244 potent antiviral activity of atazanavir and nelfinavir against SARS-CoV-2, it might be interesting

245 to conduct resistance selection to elucidate their drug target(s). 
A
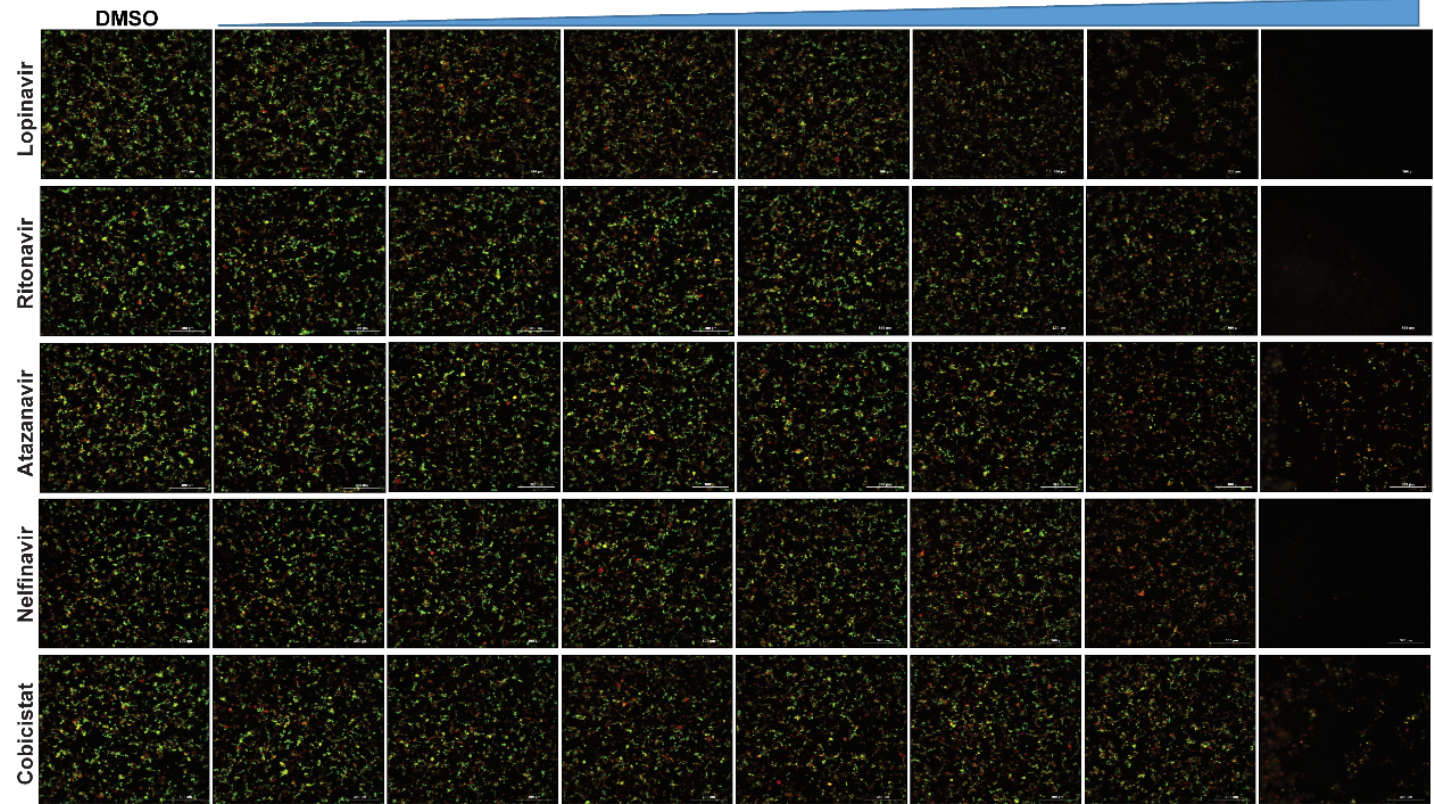

B

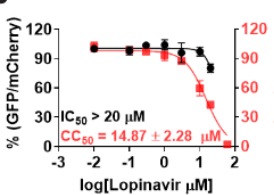

G

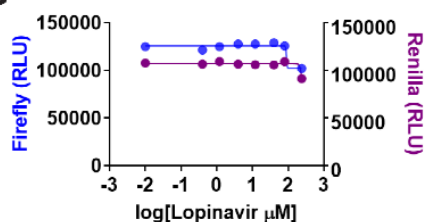

I

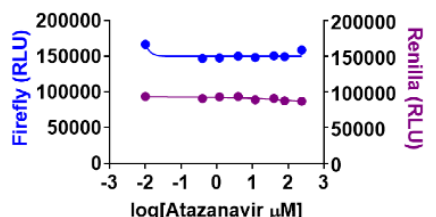

K

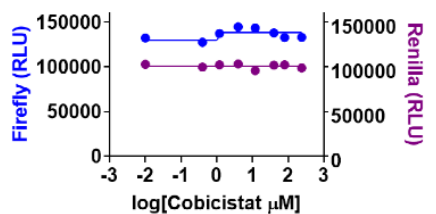

C

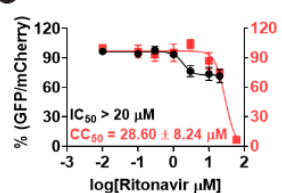

D

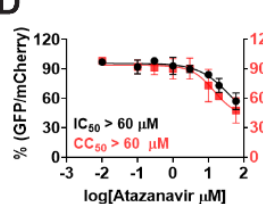

E

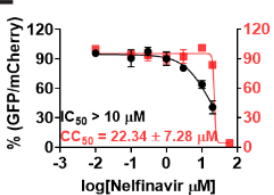

F

$\mathrm{H}$
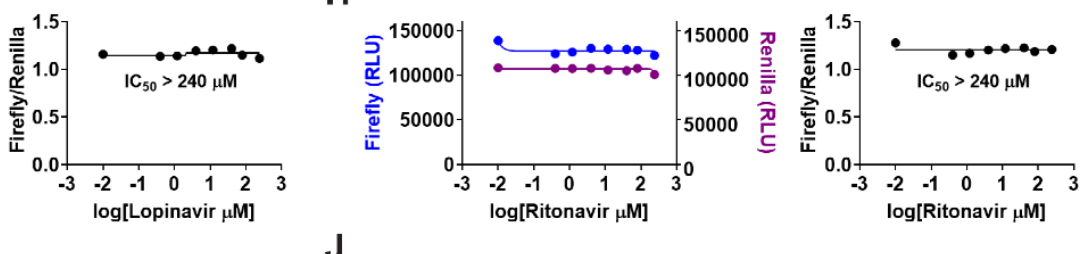

J
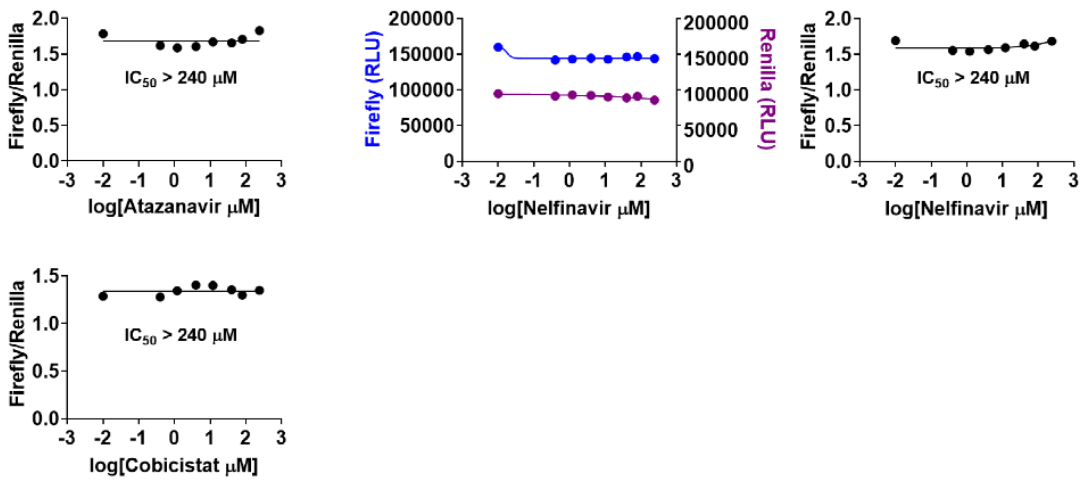

Figure 3: Validation/invalidation of HIV protease inhibitors lopinavir, ritonavir, atazanavir, nelfinavir, and cobicistat as SARS CoV-2 $\mathrm{M}^{\text {pro }}$ inhibitors using the Flip-GFP assay and ProteaseGlo luciferase assay. (A) Representative images from the Flip-GFP-Mpro assay. (B-F) Dose-response curve of the GFP and mCherry fluorescent signals for lopinavir (B), ritonavir $(C)$, atazanavir $(D)$, nelfinavir $(E)$, and cobicistat $(F)$; mCherry signal alone was used to 
252 normalize protein expression level or calculate compound cytotoxicity. (G-K) Protease-Glo

253 luciferase assay results of lopinavir $(\mathrm{G})$, ritonavir $(\mathrm{H})$, atazanavir $(\mathrm{I})$, nelfinavir $(\mathrm{J})$, and cobicistat

$254(\mathrm{~K})$. Left column showed Firefly and Renilla luminescence signals in the presences of increasing

255 concentrations of lopinavir, ritonavir, atazanavir, nelfinavir, and cobicistat; Right column showed

256 dose-response curve plots of ratio of FFluc/Rluc luminescence. Renilla luminescence signal

257 alone was used to normalize protein expression level. None of the compounds shows significant

258 inhibition in the presence of up to $240 \mu \mathrm{M}$ compounds.

259

\subsection{Bioactive compounds from drug repurposing}

261 Several bioactive compounds have been identified as SARS-CoV-2 Mpro inhibitors through

262 either virtual screening or FRET-based HTS. We are interested in validating these hits using the

263 Flip-GFP and the Protease-Glo luciferase assays.

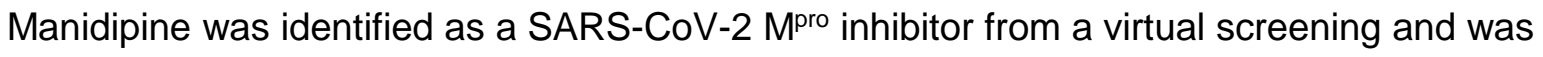
subsequently shown to inhibit $\mathrm{M}^{\text {pro }}$ with an $\mathrm{IC}_{50}$ of $4.81 \mu \mathrm{M}$ in the FRET assay ${ }^{34}$. No antiviral data was provided. When we repeated the FRET assay, the $\mathrm{IC}_{50}$ was $64.2 \mu \mathrm{M}$ (Table 2). Manidipine

267 also did not show binding to $\mathrm{M}^{\text {pro }}$ in the thermal shift assay. Furthermore, manidipine showed no

268 activity in either the Flip-GFP assay or the Protease-Glo luciferase assay (Fig. 4A, B, and F).

269 Therefore, our results invalidated manidipine as a SARS-CoV-2 $\mathrm{M}^{\text {pro }}$ inhibitor. 
A

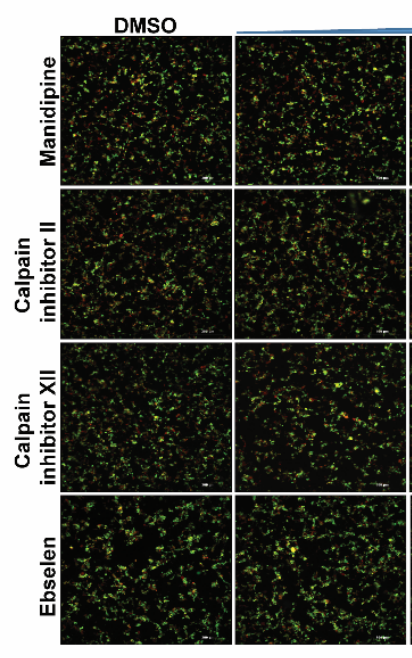

B
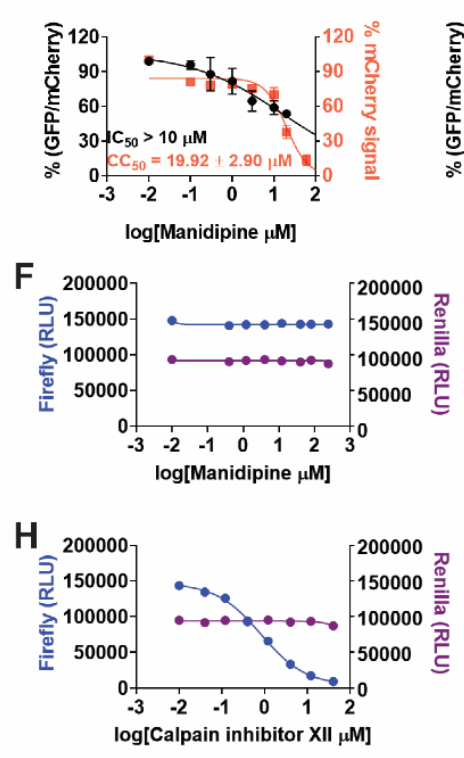

G

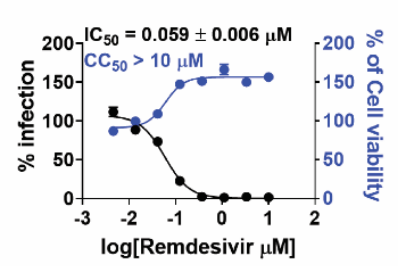

C
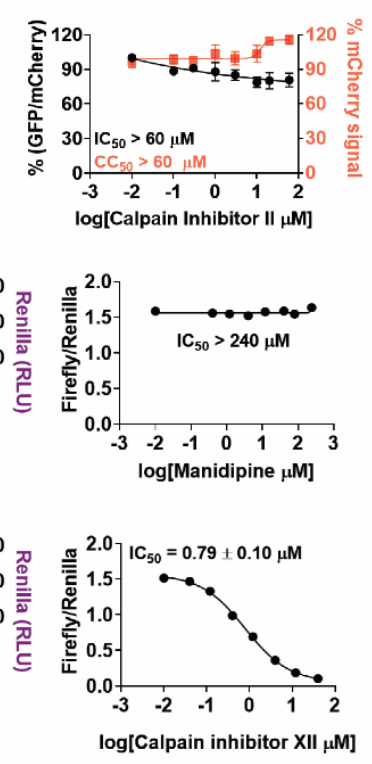

K

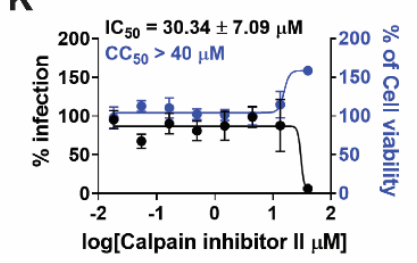

D

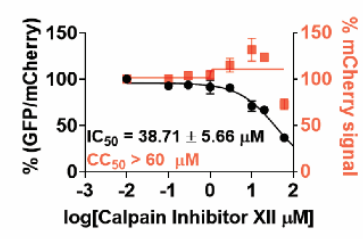

E
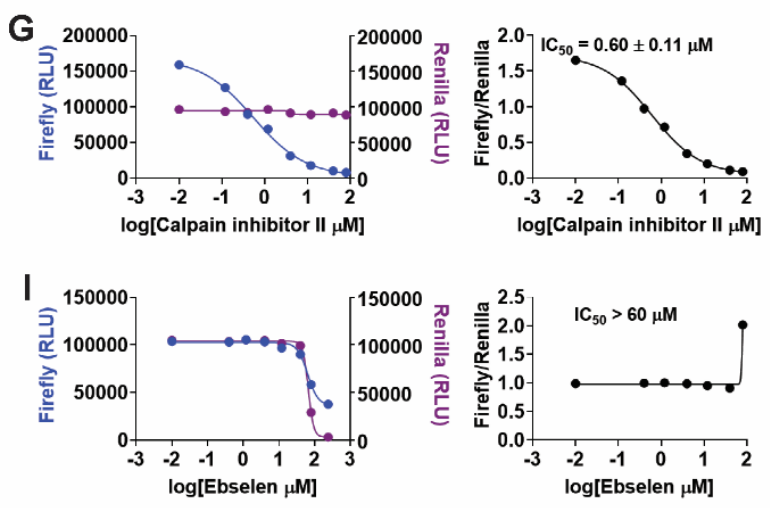

$\mathbf{L}$

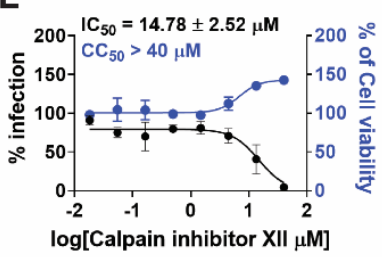

272 Figure 4. Validation/invalidation of manidipine, calpain inhibitors II and XII, and ebselen as

273 SARS CoV-2 Mpro inhibitors using the Flip-GFP assay and Protease-Glo luciferase assay. (A)

274 Representative images from the Flip-GFP-M ${ }^{\text {pro }}$ assay. (B-E) Dose-response curve of the GFP

275 and mCherry fluorescent signals for manidipine (B), calpain inhibitor II (C), calpain inhibitor XII

276 (D), and ebselen (E); mCherry signal alone was used to normalize protein expression level or

277 calculate compound cytotoxicity. (F-I) Protease-Glo luciferase assay results of manidipine (F), 
calpain inhibitor II (G), calpain inhibitor XII (H), and ebselen (I). Left column showed Firefly and Renilla luminescence signals in the presences of increasing concentrations of lopinavir, ritonavir, atazanavir, nelfinavir, and cobicistat; Right column showed dose-response curve plots of the ratio of FFluc/Rluc luminescence. Renilla luminescence signal alone was used to normalize protein expression level. (G-K) Antiviral activity of remdesivir (G), calpain inhibitor II $(\mathrm{K})$, and calpain inhibitor XII (L) against SARS-CoV-2 in Calu-3 cells.

In the same screening which we identified boceprevir as a SARS-CoV-2 Mpro inhibitor, calpain inhibitors II and XII were also found to have potent inhibition against $\mathrm{M}^{\text {pro }}$ with $\mathrm{IC}_{50}$ values of 0.97 and $0.45 \mu \mathrm{M}$ in the FRET assay ${ }^{2}$. Both compounds showed binding to $\mathrm{M}^{\text {pro }}$ in the thermal shift and native mass spectrometry assays. The Protease-Glo luciferase assay similarly confirmed the potent inhibition of calpain inhibitors II and XII against $\mathrm{M}^{\text {pro }}$ with $\mathrm{IC}_{50}$ values of 0.60 and $0.79 \mu \mathrm{M}$, respectively (Fig. 4G, H). However, calpain inhibitor II had no effect on the cellular $\mathrm{M}^{\text {pro }}$ activity as shown by the lack of inhibition in the Flip-GFP assay ( $\left.\mathrm{IC}_{50}>60 \mu \mathrm{M}\right)$ (Fig. 4A, C), while calpain inhibitor XII showed weak activity $\left(\mathrm{IC}_{50}=38.71 \mu \mathrm{M}\right)($ Fig. $4 \mathrm{~A}, \mathrm{D})$. A recent study by Liu et al using a $\mathrm{M}^{\text {pro }}$ trigged cytotoxicity assay similarly found the lack of cellular $\mathrm{M}^{\text {pro }}$ inhibition by calpain inhibitors II and XII ${ }^{51}$. These results contradict to the potent antiviral activity of both compounds in Vero E6 cells ${ }^{2}$. It is noted that calpain inhibitors II and XII are also potent inhibitors of cathepsin $L$ with $\mathrm{IC}_{50}$ values of 0.41 and $1.62 \mathrm{nM}$, respectively ${ }^{3}$. One possible explanation is that the antiviral activity of calpain inhibitors II and XII against SARS-CoV-2 might be cell type dependent, and the observed inhibition in Vero E6 cells might be due to cathepsin $L$ inhibition instead of $\mathrm{M}^{\text {pro }}$ inhibition. Vero E6 cells are TMPRSS2 negative, and SARS-CoV-2 enters cell mainly through endocytosis and is susceptible to cathepsin $L$ inhibitors ${ }^{52}$. To further evaluate the antiviral activity of calpain inhibitors II and XII against SARS-CoV-2, we tested them in Calu-3 cells using the immunofluorescence assay (Fig. 4G, K, L). Calu-3 is TMPRSS2 positive and it is a close mimetic of the human primary epithelial cell ${ }^{53}$. As expected, calpain inhibitors II and XII displayed much weaker antiviral activity against SARS-CoV-2 in Calu-3 cells than in Vero E6 cells with $\mathrm{EC}_{50}$ values of 30.34 and $14.78 \mu \mathrm{M}$, respectively (Fig. 4K, L). These results suggest that the Flip-GFP assay can be used to faithfully predict the antiviral activity of $\mathrm{M}^{\text {pro }}$ inhibitors. The lower activity of calpain inhibitors II and XII in the Flip-GFP assay and the Calu-3 antiviral assay might due to the competition with host proteases, resulting in the lack of cellular target engagement with $\mathrm{M}^{\text {pro }}$. 
such as Calu-3 should be used to test the antiviral activity of calpain inhibitors II and XII analogs.

Ebselen is among one of the most frequently reported promiscuous $\mathrm{M}^{\text {pro inhibitors. It was }}$ first reported by Yang et al that ebselen inhibits SARS-CoV-2 $\mathrm{M}^{\text {pro }}$ with an $\mathrm{IC}_{50}$ of $0.67 \mu \mathrm{M}$ and the SARS-CoV-2 replication with an $\mathrm{EC}_{50}$ of $4.67 \mu \mathrm{M}^{8}$. However, it was noted that no reducing reagent was added in the FRET assay, and we reasoned that the observed inhibition might be due to non-specific modification of the catalytic cysteine 145 by ebselen. To test this hypothesis, we repeated the FRET assay with and without reducing reagent DTT or GSH, and found that ebselen completely lost the $\mathrm{M}^{\text {pro }}$ inhibition in the presence of DTT or $\mathrm{GSH}^{35}$. Similarly, ebselen also non-specifically inhibited several other viral cysteine proteases in the absence of DTT including SARS-CoV-2 PL pro, EV-D68 2A ${ }^{\text {pro }}$ and 3C ${ }^{\text {pro }}$, and EV-A71 2A ${ }^{\text {pro }}$ and $3 C^{\text {pro35. }}$. The inhibition was abolished with the addition of DTT. Ebselen also had no antiviral activity against EV-A71 and EV-D68, suggesting that the FRET assay results without reducing reagent cannot be used to predict the antiviral activity. In this study, we found that ebselen showed no inhibition in either the Flip-GFP assay or the split-luciferase assay (Fig. 4A, E, I), providing further evidence for the promiscuous mechanism of action of ebselen. Another independent study by Deval et al using mass spectrometry assay reached similar conclusion that the inhibition of $\mathrm{M}^{\text {pro }}$ by ebselen is non-specific and inhibition was abolished with the addition of reducing reagent DTT or glutathione ${ }^{54}$. In contrary to the potent antiviral activity reported by Yang et al, the study from Deval et al found that ebselen was inactive against SARS-CoV-2 in Vero E6 cells $\left(E_{50}>\right.$ $100 \mu \mathrm{M})$. Lim et al reported that ebselen and disulfiram had synergistic antiviral effect with remdesivir against SARS-CoV-2 in vero E6 cells ${ }^{55}$. It was proposed that ebselen and disulfiram act as zinc ejectors and inhibited not only the PL ${ }^{\text {pro56, }}$, but also the nsp13 ATPase and nsp14 exoribonuclease activities ${ }^{55}$, further casting doubt on the detailed mechanism of action of ebselen.

Despite the accumulating evidence to support the promiscuous mechanism of action of ebselen, several studies continue to explore ebselen and its analogs as SARS-CoV-2 $\mathrm{M}^{\text {pro }}$ and $P^{\text {pro inhibitors }}{ }^{36,57,58}$. A number of ebselen analogs were designed and found to have comparable enzymatic inhibition and antiviral activity as ebselen. MR6-31-2 had slightly weaker enzymatic inhibition against SARS-CoV-2 $\mathrm{M}^{\text {pro }}$ compared to ebselen ( $\mathrm{IC}_{50}=0.824$ vs $\left.0.67 \mu \mathrm{M}\right)$, however, MR6-31-2 had more potent antiviral activity than ebselen $\left(\mathrm{EC}_{50}=1.78\right.$ vs $\left.4.67 \mu \mathrm{M}\right)$ against SARS-CoV-2 $\mathrm{M}^{\text {pro }}$ in Vero E6 cells. X-ray crystallization of SARS-CoV-2 M ${ }^{\text {pro }}$ with MR631-2 (PDB: 7BAL) and ebselen (PDB: 7BAK) revealed nearly identical complex structures. It 
344

345

346

347

348

349

350

351

352

353

354

355

356

357

358

359

360

361

362

363

364

365

366

367

368

369

370

371

372

373

374

was found that selenium coordinates directly to Cys145 and forms a S-Se bond ${ }^{36}$. Accordingly, a mechanism involving hydrolysis of the organoselenium compounds was proposed. Similar to their previous study, the $\mathrm{M}^{\text {pro }}$ enzymatic reaction buffer (50 mM Tris $\mathrm{pH}$ 7.3, $1 \mathrm{mM}$ EDTA) did not include the reducing reagent DTT. Therefore, the $\mathrm{M}^{\text {pro }}$ inhibition by these ebselen analogs might be non-specific and the antiviral activity might arise from other mechanisms. ${ }^{36}$

Overall, it can be concluded that ebselen is not a specific $\mathrm{M}^{\text {pro }}$ inhibitor, and its antiviral activity against SARS-CoV-2 might involve other drug targets such as nsp13 or nsp14.

Disulfiram is an FDA-approved drug for alcohol aversion therapy. Disulfiram has a polypharmacology and was reported to inhibit multiple enzymes including urease ${ }^{59}$, methyltransferase ${ }^{60}$, and kinase ${ }^{59}$ through reacting with cysteine residues. Disulfiram was also reported as an allosteric inhibitor of MERS-CoV $\mathrm{PL}^{\text {pro61 }}$. Yang et al reported disulfiram as a $\mathrm{M}^{\text {pro }}$ inhibitor with an $\mathrm{IC}_{50}$ of $9.35 \mu \mathrm{M}$. Follow up studies by us and others showed that disulfiram did not inhibit $\mathrm{M}^{\text {pro }}$ in the presence of DTT. In this study, disulfiram had no inhibition against $\mathrm{M}^{\text {pro }}$ in either the Flip-GFP assay or the Protease-Glo luciferase assay (Fig. 5A, B, N).

Similar to disulfiram, carmofur, PX-12 and tideglusib, which were previously claimed by

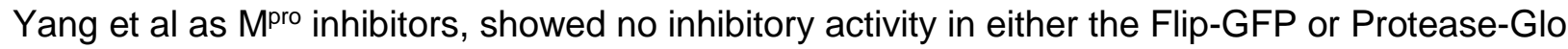
luciferase assay (Fig. 5A, C, D, E, O, P, Q), which is consistent with their lack of inhibition in the FRET assay in the presence of DTT ${ }^{35}$.

Shikonin and baicalein are polyphenol natural products with known polypharmacology. Both compounds showed no inhibition in either the Flip-GFP or the Protease-Glo luciferase assay

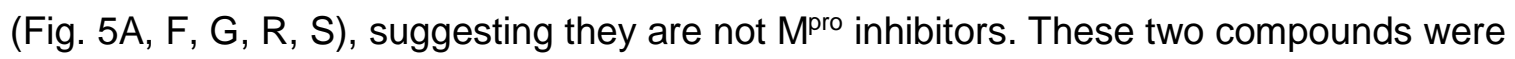
previously reported to inhibit SARS-CoV-2 $\mathrm{M}^{\text {pro }}$ in the FRET assay ${ }^{8}$ and had antiviral activity against SARS-CoV-2 in Vero E6 cells. However, our recent study showed that shikonin had no inhibition against SARS-CoV-2 $\mathrm{M}^{\text {pro }}$ in the FRET assay in the presence of $\mathrm{DTT}^{35}$. Studies from Deval et al using FRET assay and mass spectrometry assay reached the same conclusion. Xray crystal structure of SARS-CoV-2 $\mathrm{M}^{\text {pro }}$ in complex with Shikonin showed that shikonin binds to the active site in a non-covalent manner. ${ }^{9}$

In addition to the proposed mechanism of action of $\mathrm{M}^{\text {pro }}$ inhibition, Schinazi et al showed that baicalein and baicalin inhibit the SARS-CoV-2 RNA-dependent RNA polymerase ${ }^{62}$. Overall, shikonin and baicalein are not $\mathrm{M}^{\text {pro }}$ inhibitors and the antiviral activity of baicalein against SARSCoV-2 might involve other mechanisms. 


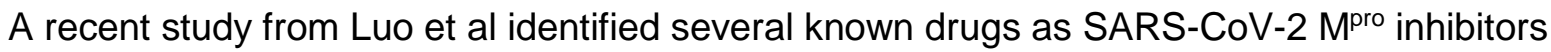

376 from a virtual screening ${ }^{63}$. The identified compounds include chloroquine $\left(\mathrm{IC}_{50}=3.9 \pm 0.2 \mu \mathrm{M} ; \mathrm{K}_{\mathrm{i}}\right.$

$377=0.56 \pm 0.12 \mu \mathrm{M})$, hydroxychloroquine $\left(\mathrm{IC}_{50}=2.9 \pm 0.3 \mu \mathrm{M} ; \mathrm{K}_{\mathrm{i}}=0.36 \pm 0.21 \mu \mathrm{M}\right)$,

378 oxytetracycline $\left(\mathrm{IC}_{50}=15.2 \pm 0.9 \mu \mathrm{M} ; \mathrm{K}_{\mathrm{i}}=0.99 \pm 0.06 \mu \mathrm{M}\right)$, montelukast $\left(\mathrm{IC}_{50}=7.3 \pm 0.5 \mu \mathrm{M} ; \mathrm{K}_{\mathrm{i}}\right.$

$379=0.48 \pm 0.04 \mu \mathrm{M})$, candesartan $\left(\mathrm{IC}_{50}=2.8 \pm 0.3 \mu \mathrm{M} ; \mathrm{K}_{\mathrm{i}}=0.18 \pm 0.02 \mu \mathrm{M}\right)$, and dipyridamole $\left(\mathrm{K}_{\mathrm{i}}\right.$

$380=0.04 \pm 0.001 \mu \mathrm{M})$. The discovery of chloroquine and hydroxychloroquine as $\mathrm{M}^{\text {pro }}$ inhibitor was

381 particularly intriguing. Several high-throughput screenings have been conducted for $\mathrm{M}^{\text {pro24, 64, }}$,

382 and chloroquine and hydroxychloroquine were not among the list of active hits. In our follow up

383 study, we found that none of the identified hits reported by Luo et al inhibited $\mathrm{M}^{\text {pro }}$ either with or

384 without DTT in the FRET assay ${ }^{30}$. In corroborate with our previous finding, the Flip-GFP and

385 Protease-Glo luciferase assays similarly confirmed the lack of inhibition of these compounds

386 against $\mathrm{M}^{\text {pro }}$ (Fig. 5A, H-M, T-Y). Therefore, it can be concluded that chloroquine,

387 hydroxychloroquine, oxytetracycline, montelukast, candesartan, and dipyridamole are not

388 SARS-CoV-2 Mpro inhibitors. Other than the claims made by Luo et al, no other studies have independently confirmed these compounds as $\mathrm{M}^{\text {pro }}$ inhibitors. 


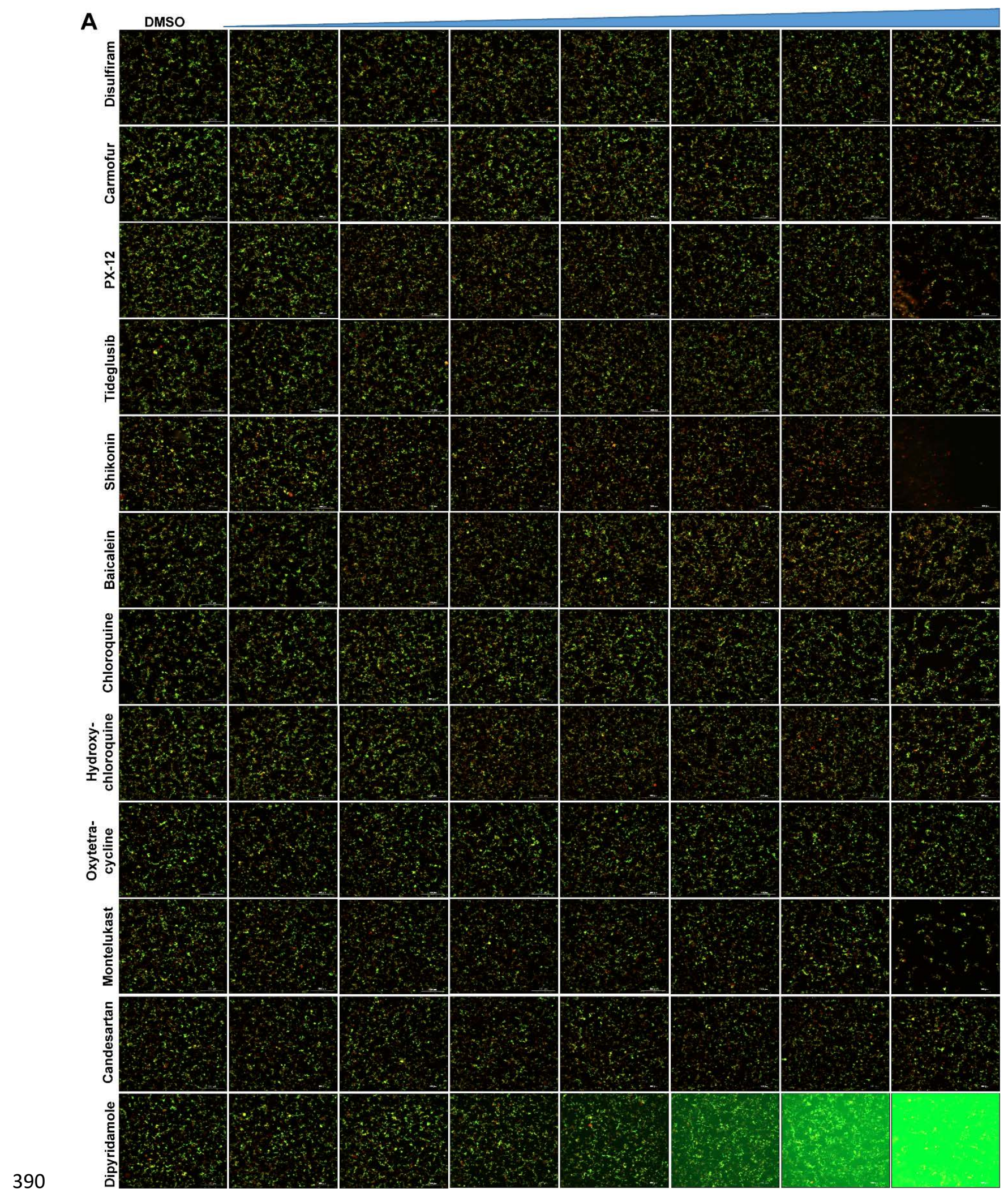


bioRxiv preprint doi: https://doi.org/10.1101/2021.08.28.458041; this version posted August 30, 2021. The copyright holder for this preprint (which was not certified by peer review) is the author/funder, who has granted bioRxiv a license to display the preprint in perpetuity. It is made available under aCC-BY 4.0 International license.

B

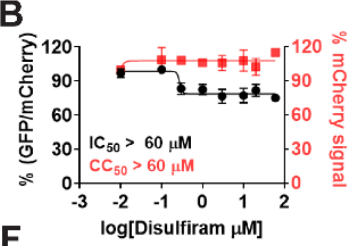

$\mathbf{F}$

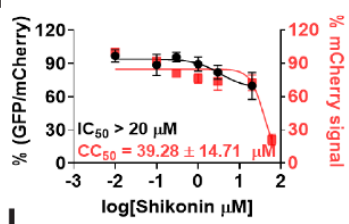

J

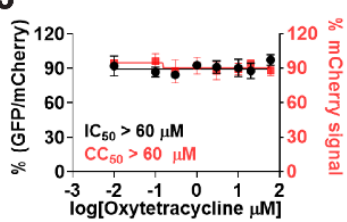

C

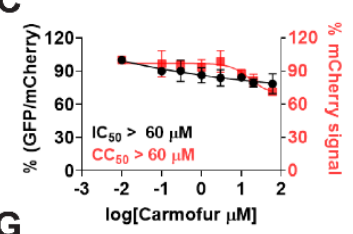

G

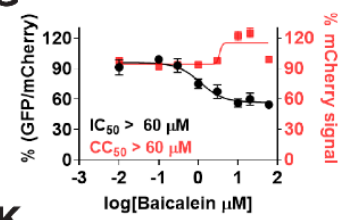

K

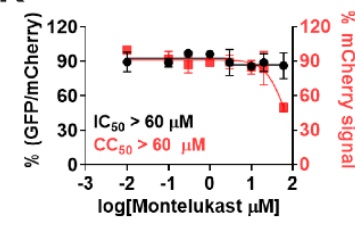

D

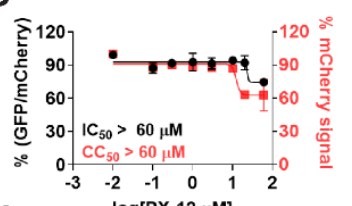

$\mathrm{H}$

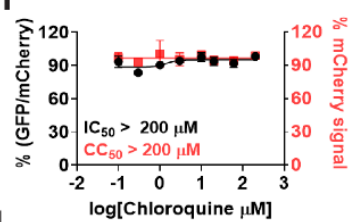

L

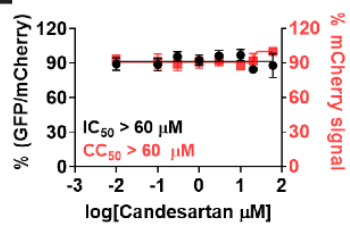

E

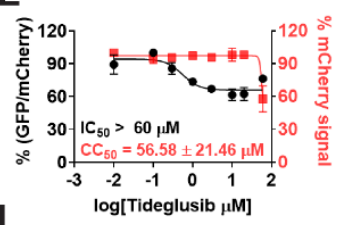

I

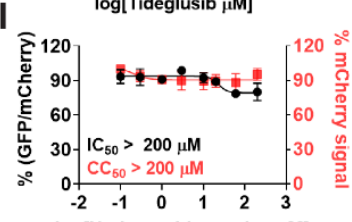

$M$

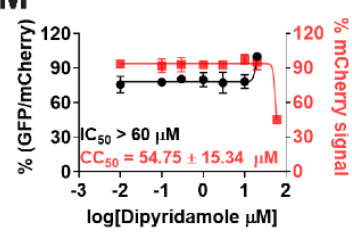

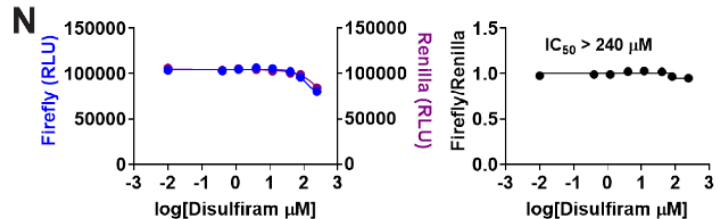

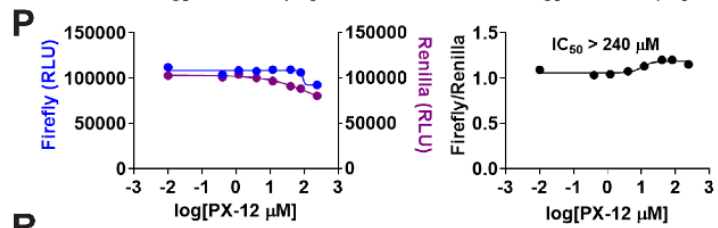

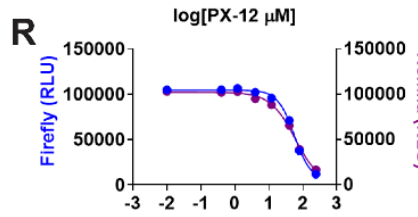
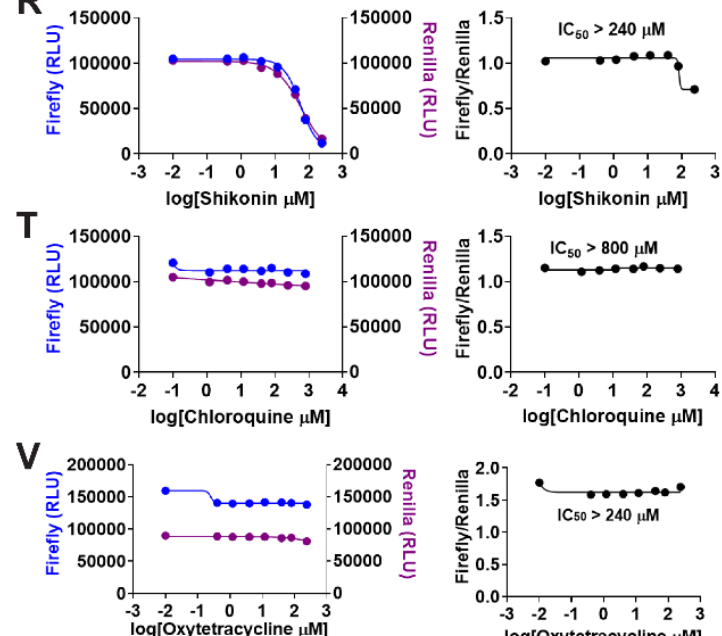

log[Shikonin $\mu \mathrm{M}]$

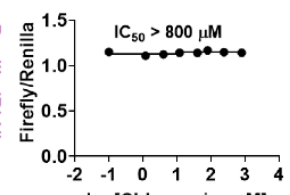

log[Chloroquine $\mu \mathrm{M}]$

392

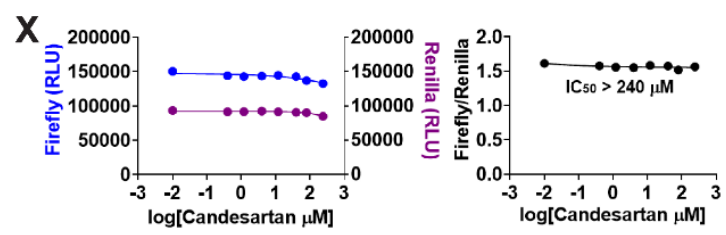

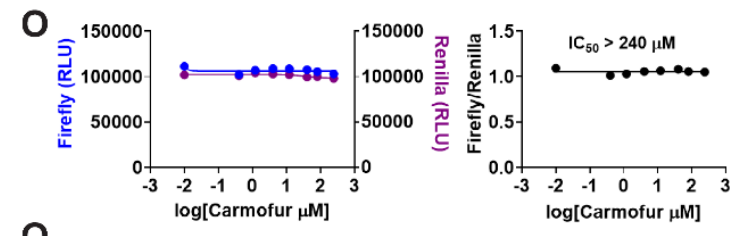

Q

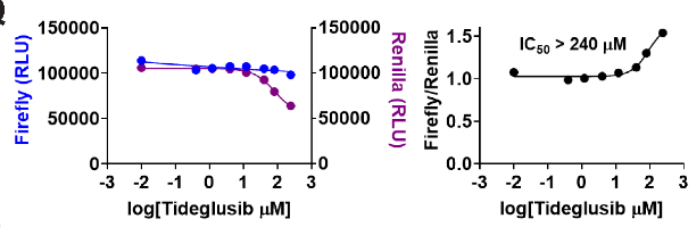

S
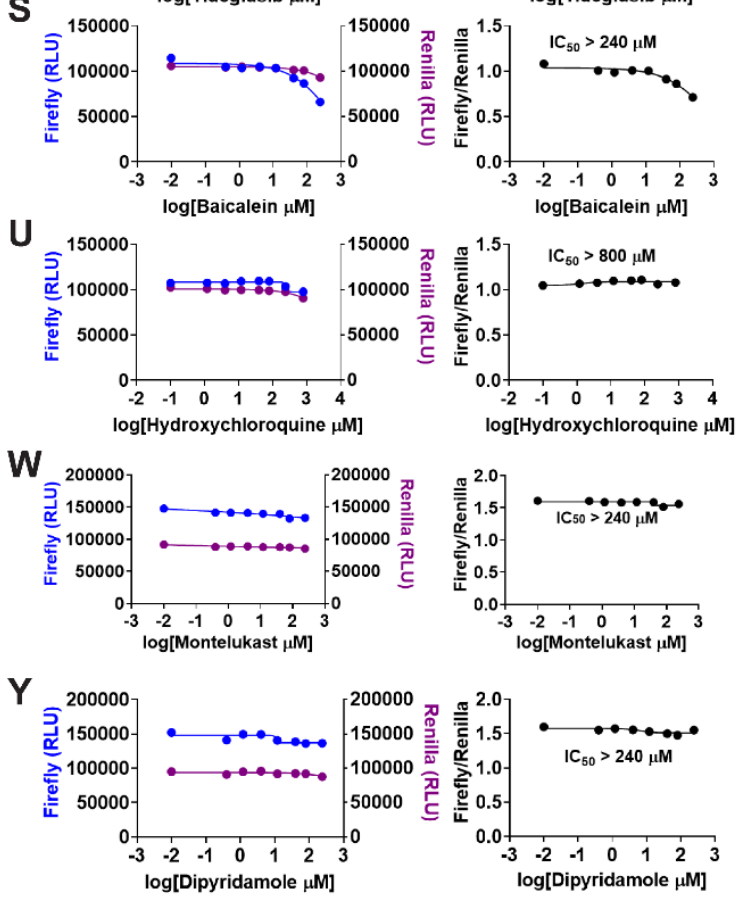
Figure 5. Validation/invalidation of disulfiram, carmofur, PX-12, tideglusib, shikonin, baicalein, chloroquine, hydroxychloroquine, oxytetracycline, montelukast, candesartan, and dipyridamole

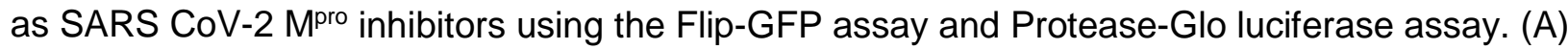
Representative images from the Flip-GFP-Mpro assay. (B-E) Dose-response curve of the ratio of GFP/mCherry fluorescent signal for disulfiram (B), carmofur (C), PX-12 (D), tideglusib (E), shikonin $(F)$, baicalein $(G)$, chloroquine $(H)$, hydroxychloroquine $(I)$, oxytetracycline $(J)$, montelukast (K), candesartan (L), and dipyridamole (M); mCherry signal alone was used to normalize protein expression level or calculate compound cytotoxicity. (N-Y) Protease-Glo luciferase assay results of disulfiram $(\mathrm{N})$, carmofur $(\mathrm{O}), \mathrm{PX}-12(\mathrm{P})$, tideglusib $(\mathrm{Q})$, shikonin $(\mathrm{R})$, baicalein $(S)$, chloroquine $(T)$, hydroxychloroquine $(U)$, oxytetracycline $(V)$, montelukast $(\mathrm{W})$, candesartan (X), and dipyridamole $(Y)$. Left column showed Firefly and Renilla luminescence signals in the presences of increasing concentrations of disulfiram, carmofur, PX-12, tideglusib, shikonin, baicalein, chloroquine, hydroxychloroquine, oxytetracycline, montelukast, candesartan, and dipyridamole; Right column showed dose-response curve plots of the ratio of FFluc/Rluc luminescence. Renilla luminescence signal alone was used to normalize protein expression level.

\section{CONCLUSION}

The $\mathrm{M}^{\text {pro }}$ is perhaps the most extensive exploited drug target for SARS-CoV-2. A variety of drug discovery techniques have been applied to search for $\mathrm{M}^{\text {pro }}$ inhibitors. Researchers around the world are racing to share their findings with the scientific community to expedite the drug discovery process. However, the quality of science should not be compromised by the speed.

The mechanism of action of drug candidates should be thoroughly characterized in biochemical, binding, and cellular assays. Pharmacological characterization should address both target specificity and cellular target engagement. For target specificity, the drug candidates can be counter screened against unrelated cysteine proteases such as the viral EV-A71 2A pro, EV-D68 $2 \mathrm{~A}^{\text {pro }}$, the host cathepsins B, L, and K, caspase, calpains I, II, and III, and etc. Compounds inhibit multiple cysteine proteases non-discriminately are most likely promiscuous compounds that act through redox cycling, inducing protein aggregation, or alkylating catalytic cysteine residue C145. For cellular target engagement, the Flip-GFP and Protease-Glo luciferase assays can be applied. Both assays are performed in the presence of competing host proteins at the cellular environment. Collectively, our study reaches the following conclusions: 1) for validated $\mathrm{M}^{\text {pro }}$ inhibitors, the $\mathrm{IC}_{50}$ values with and without reducing reagent should be about the same in 
the FRET assay; 2) validated $\mathrm{M}^{\text {pro }}$ inhibitors should show consistent results in the FRET assay, thermal shift binding assay, and the Protease-Glo luciferase assay. For compounds that are not cytotoxic, they should also be active in the Flip-GFP assay; 3) compounds that have antiviral activity but lack consistent results from the FRET, thermal shift, Flip-GFP, and Protease-Glo

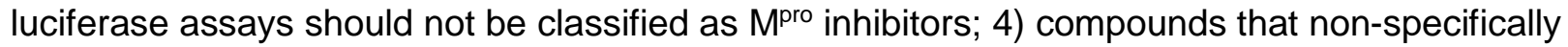
inhibit multiple unrelated viral or host cysteine proteases are most likely promiscuous inhibitors that should be triaged. 5) X-ray crystal structures cannot be used to justify the target specificity or cellular target engagement. Promiscuous compounds have been frequently co-crystallized with $\mathrm{M}^{\text {pro }}$ including ebselen, carmofur, and shikonin (Table 2).

Overall, we hope our studies will promote the awareness of the promiscuous SARS-CoV-2

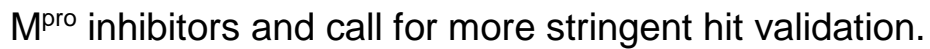

\section{MATHODS AND MATERIALS}

Protein Expression and Purification. The tag-free SARS CoV-2 $\mathrm{M}^{\text {pro }}$ protein with native Nand C- termini was expressed in pSUMO construct as described previously ${ }^{3}$.

Enzymatic Assays. The FRET-based protease was performed as described previously². Briefly, $100 \mathrm{nM}$ of $\mathrm{M}^{\text {pro }}$ protein in the reaction buffer containing $20 \mathrm{mM} \mathrm{HEPES}, \mathrm{pH}$ 6.5, $120 \mathrm{mM}$ $\mathrm{NaCl}, 0.4 \mathrm{mM}$ EDTA, 4 mM DTT, and 20\% glycerol was incubated with serial concentrations of the testing compounds at $30^{\circ} \mathrm{C}$ for $30 \mathrm{~min}$. The proteolytic reactions were initiated by adding 10 $\mu \mathrm{M}$ of FRET- peptide substrate (Dabcyl-KTSAVLQ/SGFRKME(Edans)) and recorded in Cytation 5 imaging reader (Thermo Fisher Scientific) with 360/460 filter cube for $1 \mathrm{hr}$. The proteolytic reaction initial velocity in the presence or absence of testing compounds was determined by linear regression using the data points from the first $15 \mathrm{~min}$ of the kinetic progress curves. $\mathrm{IC}_{50}$ values was calculated by a 4-parameter dose-response function in prism 8.

\section{Thermal shift assay (TSA). Direct binding of testing compounds to SARS CoV-2 $\mathrm{M}^{\text {pro }}$ protein} was evaluated by differential scanning fluorimetry (DSF) using a Thermal Fisher QuantStudio 5 Real-Time PCR System as previously described ${ }^{2}$. Briefly, SARS CoV-2 Mro protein was diluted into reaction buffer to a final concentration of $3 \mu \mathrm{M}$ and incubated with $40 \mu \mathrm{M}$ of testing compounds at $30^{\circ} \mathrm{C}$ for $30 \mathrm{~min}$. DMSO was included as a reference. SYPRO orange (1x, Thermal Fisher, catalog no. S6650) was added, and the fluorescence signal was recorded 
under a temperature gradient ranging from 20 to $95^{\circ} \mathrm{C}$ with incremental step of $0.05^{\circ} \mathrm{C} \mathrm{s}^{-1}$. The melting temperature $\left(T_{m}\right)$ was calculated as the mid log of the transition phase from the native to the denatured protein using a Boltzmann model in Protein Thermal Shift Software v1.3. $\Delta T_{m}$ was the difference between $T_{m}$ in the presence of testing compounds and $T_{m}$ in the presence of

463 DMSO.

Flip-GFP M ${ }^{\text {pro }}$ Assay. The construction of FlipGFP-M ${ }^{\text {pro }}$ plasmid was described previously ${ }^{11}$. The assay was carried out as follows: 293T cells were seeded in 96-well black, clear bottomed Greiner plate (catalog no. 655090) and incubated overnight to reach 70-90\% confluency. 50 ng of FlipGFP-Mpro plasmid and 50 ng SARS CoV-2 Mpro expression plasmid pcDNA3.1 SARSCoV$2 \mathrm{M}^{\text {pro }}$ were transfected into each well with transfection reagent TransIT-293 (Mirus catalog no. MIR 2700) according to the manufacturer's protocol. Three hours after transfection, $1 \mu \mathrm{L}$ of 471 testing compound was directly added to each well without medium change. Two days after

472 transfection, images were taken with Cytation 5 imaging reader (Biotek) using GFP and

473 mCherry channels via 10× objective lens and were analyzed with Gen5 3.10 software (Biotek).

474 The mCherry signal alone in the presence of testing compounds was utilized to evaluate the compound cytotoxicity.

Protease-Glo luciferase assay. pGlosensor-30F DEVD vector was obtained from Promega

478 (Catlog no. CS182101). pGloSensor-30F Mro plasmid was generated by replacing the original caspase cutting sequence (DEVDG) was with SARS CoV-2 $\mathrm{M}^{\text {pro }}$ cutting sequence generated by annealing two 5'-phosphoriated primers: forward: as follows: $293 \mathrm{~T}$ cells in $10 \mathrm{~cm}$ culture dish were transfected with pGlosensor-30F $\mathrm{M}^{\text {pro }}$ plasmid in the presence of transfection reagent TransIT-293 (Mirus catalog no. MIR 2700) according to the manufacturer's protocol. $24 \mathrm{hrs}$ after transfection, cells were washed with PBS once, then

487 each dish of cells was lysed with $5 \mathrm{ml}$ of PBS+1\% Trition-X100; cell debris was removed by 488 centrifuge at $2000 \mathrm{~g}$ for $10 \mathrm{~min}$. Cell lysates was freshly frozen to $-80^{\circ} \mathrm{C}$ until ready to use.

489 During the assay, $20 \mu \mathrm{l}$ cell lysate was added to each well in 96-well flat bottom white plate 490 (Fisherbrand Catalog no. 12566619), then $1 \mu \mathrm{l}$ of testing compound or DMSO was added to 491 each well and mixed at room temperature for $5 \mathrm{~min} .5 \mu \mathrm{l}$ of $200 \mathrm{nM}$ E. Coli expressed SARS 492 CoV-2 Mpro protein was added to each well to initiate the proteolytic reaction (the final $\mathrm{M}^{\text {pro }}$ 
protein concentration is around $40 \mathrm{nM}$ ). The reaction mix was further incubated at $30^{\circ} \mathrm{C}$ for 30 min. The firefly and renilla luciferase activity were determined with Dual-Glo Luciferase Assay according to manufacturer's protocol (Promega Catalog no. E2920). The efficacy of testing compounds against $\mathrm{M}^{\text {pro }}$ was evaluated by plotting the ratio of firefly luminescence signal over the renilla luminescence signal versus the testing compound concentrations with a 4-parameter dose-response function in prism 8.

Antiviral assay in Calu-3 cells. The antiviral assay was performed as previously described ${ }^{65}$. Calu-3 cells (ATCC, HTB-55) were plated in 384 well plates and grown in Minimal Eagles Medium supplemented with 1\% non-essential amino acids, 1\% penicillin/streptomycin, and 10\% FBS. The next day, $50 \mathrm{~nL}$ of compound in DMSO was added as an 8-pt dose response with three-fold dilutions between testing concentrations in triplicate, starting at $40 \mu \mathrm{M}$ final concentration. The negative control (DMSO, $\mathrm{n}=32)$ and positive control (10 $\mu \mathrm{M}$ Remdesivir, $n=32$ ) were included on each assay plate. Calu-3 cells were pretreated with controls and testing compounds (in triplicate) for 2 hours prior to infection. In BSL-3 containment, SARS-CoV-2 (isolate USA-WA1/2020) diluted in serum free growth medium was added to plates to achieve an $\mathrm{MOI}$ of 0.5 . Cells were incubated with compounds and SARS-CoV-2 virus for 48 hours. Cells were fixed and then immunostained with anti-dsRNA (J2) and nuclei were counterstained with Hoechst 33342 for automated microscopy. Automated image analysis quantifies the number of cells per well (toxicity) and the percentage of infected cells (dsRNA+ cells/cell number) per well. SARS-CoV-2 infection at each drug concentration was normalized to aggregated DMSO plate control wells and expressed as percentage-of-control (POC=\% Infection sample/Avg \% Infection DMso cont). A non-linear regression curve fit analysis (GraphPad Prism 8) of POC Infection and cell viability versus the $\log _{10}$ transformed concentration values to calculate $\mathrm{EC}_{50}$ values for Infection and $\mathrm{CC}_{50}$ values for cell viability. Selectivity index (SI) was calculated as a ratio of drug's $\mathrm{CC}_{50}$ and $\mathrm{EC}_{50}$ values $\left(\mathrm{SI}=\mathrm{CC}_{50} / \mathrm{IC}_{50}\right)$.

\section{Author contributions}

Chunlong Ma performed the Flip-GFP assay, Protease-Glo luciferase assay, and thermal shift assay with the assistance from Haozhou Tan. Juliana Choza and Yuying Wang expressed the $\mathrm{M}^{\text {pro }}$ and performed the FRET assay. Jun Wang wrote the draft manuscript with the input from others; Jun Wang submitted this manuscript on behalf of other authors. 


\section{Declaration of competing interest}

527 The authors have no conflicts of interest to declare.

\section{Acknowledgments}

530 This research was supported by the National Institute of Allergy and Infectious Diseasess of

531 Health (NIH) (grants Al147325, Al157046, and Al158775) and the Arizona Biomedical Research

532 Commission Centre Young Investigator grant (ADHS18-198859) to J. W. The SARS-CoV-2

533 antiviral assay in Calu-3 cells was conducted by Drs. David Schultz and Sara Cherry at the

534 University of Pennsylvania through the NIAID preclinical service under a non-clinical evaluation

535 agreement.

536

\section{References}

538

5391 Hu B, Guo H, Zhou P, Shi ZL. Characteristics of SARS-CoV-2 and COVID-19. Nat Rev Microbiol 2021; 19: 141-54.

5412 Ma C, Sacco MD, Hurst B, Townsend JA, Hu Y, Szeto T, et al. Boceprevir, GC-376, and calpain inhibitors II, XII inhibit SARS-CoV-2 viral replication by targeting the viral main

5443 Sacco MD, Ma C, Lagarias P, Gao A, Townsend JA, Meng X, et al. Structure and inhibition of the SARS-CoV-2 main protease reveal strategy for developing dual

5474 Rut W, Groborz K, Zhang L, Sun X, Zmudzinski M, Pawlik B, et al. SARS-CoV-2 M(pro) $548 \quad$ inhibitors and activity-based probes for patient-sample imaging. Nat Chem Biol 2021; 17: 549 222-8.

5505 Ghosh AK, Brindisi M, Shahabi D, Chapman ME, Mesecar AD. Drug Development and 551 Medicinal Chemistry Efforts toward SARS-Coronavirus and Covid-19 Therapeutics.

$552 \quad$ ChemMedChem 2020; 15: 907-32.

5536 Ullrich S, Nitsche C. The SARS-CoV-2 main protease as drug target. Bioorg Med Chem $554 \quad$ Lett 2020; 30: 127377. 
5557 Vatansever EC, Yang KS, Drelich AK, Kratch KC, Cho CC, Kempaiah KR, et al. Bepridil

556 is potent against SARS-CoV-2 in vitro. Proc Natl Acad Sci U S A 2021; 118:

$557 \quad$ e2012201118.

5588 Jin Z, Du X, Xu Y, Deng Y, Liu M, Zhao Y, et al. Structure of M(pro) from SARS-CoV-2

$559 \quad$ and discovery of its inhibitors. Nature 2020; 582: 289-93.

5609 Li J, Zhou X, Zhang Y, Zhong F, Lin C, McCormick PJ, et al. Crystal structure of SARSCoV-2 main protease in complex with the natural product inhibitor shikonin illuminates a unique binding mode. Sci Bull (Beijing) 2021; 66: 661-3.

565 broad coronavirus 3CL inhibitor that blocks replication of SARS-CoV-2. Science 2021;

12 Ma C, Sacco MD, Xia Z, Lambrinidis G, Townsend JA, Hu Y, et al. Discovery of SARS373: 931-6.

572

Xia Z, Sacco M, Hu Y, Ma C, Meng X, Zhang F, et al. Rational Design of Hybrid SARSCoV-2 Main Protease Inhibitors Guided by the Superimposed Cocrystal Structures with the Peptidomimetic Inhibitors GC-376, Telaprevir, and Boceprevir. ACS Pharmacol CoV-2 Papain-like Protease Inhibitors through a Combination of High-Throughput Screening and a FlipGFP-Based Reporter Assay. ACS Cent Sci 2021; 7: 1245-60. Froggatt HM, Heaton BE, Heaton NS. Development of a Fluorescence-Based, HighThroughput SARS-CoV-2 3CL(pro) Reporter Assay. J Virol 2020; 94: e01265-20.

58417 Xie X, Muruato AE, Zhang X, Lokugamage KG, Fontes-Garfias CR, Zou J, et al. A Li X, Lidsky P, Xiao Y, Wu C-T, Garcia-Knight M, Yang J, et al. Ethacridine inhibits SARS-CoV-2 by inactivating viral particles in cellular models. bioRxiv 2020: 2020.10.28.359042. nanoluciferase SARS-CoV-2 for rapid neutralization testing and screening of antiinfective drugs for COVID-19. Nat Commun 2020; 11: 5214. 
Fu L, Ye F, Feng Y, Yu F, Wang Q, Wu Y, et al. Both Boceprevir and GC376 efficaciously inhibit SARS-CoV-2 by targeting its main protease. Nature Communications 2020; 11: 4417.

19 Gurard-Levin ZA, Liu C, Jekle A, Jaisinghani R, Ren S, Vandyck K, et al. Evaluation of SARS-CoV-2 3C-like protease inhibitors using self-assembled monolayer desorption ionization mass spectrometry. Antiviral Res 2020; 182: 104924.

20 Vuong W, Khan MB, Fischer C, Arutyunova E, Lamer T, Shields J, et al. Feline coronavirus drug inhibits the main protease of SARS-CoV-2 and blocks virus replication. Nat Commun 2020; 11: 4282.

21 Liu C, Boland S, Scholle MD, Bardiot D, Marchand A, Chaltin P, et al. Dual inhibition of SARS-CoV-2 and human rhinovirus with protease inhibitors in clinical development. Antiviral Res 2021; 187: 105020.

22 Bafna K, White K, Harish B, Rosales R, Ramelot TA, Acton TB, et al. Hepatitis C virus drugs that inhibit SARS-CoV-2 papain-like protease synergize with remdesivir to suppress viral replication in cell culture. Cell Rep 2021; 35: 109133.

23 Kneller DW, Galanie S, Phillips G, O'Neill HM, Coates L, Kovalevsky A. Malleability of the SARS-CoV-2 3CL M(pro) Active-Site Cavity Facilitates Binding of Clinical Antivirals. Structure 2020; 28: 1313-20 e3.

24 Jan JT, Cheng TR, Juang YP, Ma HH, Wu YT, Yang WB, et al. Identification of existing pharmaceuticals and herbal medicines as inhibitors of SARS-CoV-2 infection. Proc Natl Acad Sci U S A 2021; 118.

25 Qiao J, Li YS, Zeng R, Liu FL, Luo RH, Huang C, et al. SARS-CoV-2 M(pro) inhibitors with antiviral activity in a transgenic mouse model. Science 2021; 371: 1374-8.

26 Kneller DW, Phillips G, Weiss KL, Zhang Q, Coates L, Kovalevsky A. Direct Observation of Protonation State Modulation in SARS-CoV-2 Main Protease upon Inhibitor Binding with Neutron Crystallography. J Med Chem 2021; 64: 4991-5000.

27 Bai Y, Ye F, Feng Y, Liao H, Song H, Qi J, et al. Structural basis for the inhibition of the SARS-CoV-2 main protease by the anti-HCV drug narlaprevir. Signal Transduct Target Ther 2021; 6: 51.

28 Hattori SI, Higshi-Kuwata N, Raghavaiah J, Das D, Bulut H, Davis DA, et al. GRL-0920, an Indole Chloropyridinyl Ester, Completely Blocks SARS-CoV-2 Infection. mBio 2020; 11: e01833-20. 
Choy K-T, Wong AY-L, Kaewpreedee P, Sia SF, Chen D, Hui KPY, et al. Remdesivir, lopinavir, emetine, and homoharringtonine inhibit SARS-CoV-2 replication in vitro. Antiviral Research 2020; 178: 104786.

30 Ma C, Wang J. Dipyridamole, chloroquine, montelukast sodium, candesartan, oxytetracycline, and atazanavir are not SARS-CoV-2 main protease inhibitors. Proc NatI Acad Sci U S A 2021; 118.

31 Li Z, Li X, Huang YY, Wu Y, Liu R, Zhou L, et al. Identify potent SARS-CoV-2 main protease inhibitors via accelerated free energy perturbation-based virtual screening of existing drugs. Proc Natl Acad Sci U S A 2020; 117: 27381-7.

32 Fintelman-Rodrigues N, Sacramento CQ, Ribeiro Lima C, Souza da Silva F, Ferreira AC, Mattos M, et al. Atazanavir, Alone or in Combination with Ritonavir, Inhibits SARSCoV-2 Replication and Proinflammatory Cytokine Production. Antimicrob Agents Chemother 2020; 64.

33 Gupta A, Rani C, Pant P, Vijayan V, Vikram N, Kaur P, et al. Structure-Based Virtual Screening and Biochemical Validation to Discover a Potential Inhibitor of the SARSCoV-2 Main Protease. ACS Omega 2020; 5: 33151-61.

34 Ghahremanpour MM, Tirado-Rives J, Deshmukh M, Ippolito JA, Zhang CH, Cabeza de Vaca I, et al. Identification of 14 Known Drugs as Inhibitors of the Main Protease of SARS-CoV-2. ACS Med Chem Lett 2020; 11: 2526-33.

35 Ma C, Hu Y, Townsend JA, Lagarias PI, Marty MT, Kolocouris A, et al. Ebselen, Disulfiram, Carmofur, PX-12, Tideglusib, and Shikonin Are Nonspecific Promiscuous SARS-CoV-2 Main Protease Inhibitors. ACS Pharmacol Transl Sci 2020; 3: 1265-77. Amporndanai K, Meng X, Shang W, Jin Z, Rogers M, Zhao Y, et al. Inhibition mechanism of SARS-CoV-2 main protease by ebselen and its derivatives. Nat Commun 2021; 12: 3061.

Amporndanai K, Meng X, Shang W, Jin Z, Rogers M, Zhao Y, et al. Inhibition mechanism of SARS-CoV-2 main protease by ebselen and its derivatives. Nature Communications 2021; 12: 3061.

Jin Z, Zhao Y, Sun Y, Zhang B, Wang H, Wu Y, et al. Structural basis for the inhibition of SARS-CoV-2 main protease by antineoplastic drug carmofur. Nat Struct Mol Biol 2020; 27: 529-32.

Liu H, Ye F, Sun Q, Liang H, Li C, Li S, et al. Scutellaria baicalensis extract and baicalein inhibit replication of SARS-CoV-2 and its 3C-like protease in vitro. J Enzyme Inhib Med Chem 2021; 36: 497-503. 
Su HX, Yao S, Zhao WF, Li MJ, Liu J, Shang WJ, et al. Anti-SARS-CoV-2 activities in vitro of Shuanghuanglian preparations and bioactive ingredients. Acta Pharmacol Sin 2020; 41: 1167-77.

41 Wang M, Cao R, Zhang L, Yang X, Liu J, Xu M, et al. Remdesivir and chloroquine effectively inhibit the recently emerged novel coronavirus (2019-nCoV) in vitro. Cell Res 2020; 30: 269-71.

42 Liu J, Cao R, Xu M, Wang X, Zhang H, Hu H, et al. Hydroxychloroquine, a less toxic derivative of chloroquine, is effective in inhibiting SARS-CoV-2 infection in vitro. Cell Discovery 2020; 6: 16.

43 Kneller DW, Galanie S, Phillips G, O'Neill HM, Coates L, Kovalevsky A. Malleability of the SARS-CoV-2 3CL Mpro Active-Site Cavity Facilitates Binding of Clinical Antivirals. Structure 2020; 28: 1313-20.e3.

44 Owen DR, Allerton CMN, Anderson AS, Aschenbrenner L, Avery M, Berritt S, et al. An Oral SARS-CoV-2 M<sup>pro</sup> Inhibitor Clinical Candidate for the Treatment of COVID-19. medRxiv 2021: 2021.07.28.21261232.

45 Chu CM, Cheng VCC, Hung IFN, Wong MML, Chan KH, Chan KS, et al. Role of lopinavir/ritonavir in the treatment of SARS: initial virological and clinical findings. Thorax 2004; 59: 252-6.

46 Cao B, Wang Y, Wen D, Liu W, Wang J, Fan G, et al. A Trial of Lopinavir-Ritonavir in Adults Hospitalized with Severe Covid-19. New England Journal of Medicine 2020; 382: 1787-99.

47 Lopinavir-ritonavir in patients admitted to hospital with COVID-19 (RECOVERY): a randomised, controlled, open-label, platform trial. Lancet 2020; 396: 1345-52.

48 Park SJ, Yu KM, Kim YI, Kim SM, Kim EH, Kim SG, et al. Antiviral Efficacies of FDAApproved Drugs against SARS-CoV-2 Infection in Ferrets. mBio 2020; 11.

49 Zeldin RK, Petruschke RA. Pharmacological and therapeutic properties of ritonavirboosted protease inhibitor therapy in HIV-infected patients. Journal of Antimicrobial Chemotherapy 2004; 53: 4-9.

50 Wu C-Y, Jan J-T, Ma S-H, Kuo C-J, Juan H-F, Cheng Y-SE, et al. Small molecules targeting severe acute respiratory syndrome human coronavirus. Proc Natl Acad Sci U S A 2004; 101: 10012-7.

51 Cao W, Cho C-CD, Geng ZZ, Ma XR, Allen R, Shaabani N, et al. Cellular Activities of SARS-CoV-2 Main Protease Inhibitors Reveal Their Unique Characteristics. bioRxiv 2021: 2021.06.08.447613. 
$52 \mathrm{Hu}$ Y, Ma C, Szeto T, Hurst B, Tarbet B, Wang J. Boceprevir, Calpain Inhibitors II and XII, and GC-376 Have Broad-Spectrum Antiviral Activity against Coronaviruses. ACS Infect Dis 2021; 7: 586-97.

53 Hoffmann M, Kleine-Weber H, Schroeder S, Kruger N, Herrler T, Erichsen S, et al. SARS-CoV-2 Cell Entry Depends on ACE2 and TMPRSS2 and Is Blocked by a Clinically Proven Protease Inhibitor. Cell 2020; 181: 271-80 e8.

54 Gurard-Levin ZA, Liu C, Jekle A, Jaisinghani R, Ren S, Vandyck K, et al. Evaluation of SARS-CoV-2 3C-like protease inhibitors using self-assembled monolayer desorption ionization mass spectrometry. Antiviral Research 2020; 182: 104924.

55 Chen T, Fei C-Y, Chen Y-P, Sargsyan K, Chang C-P, Yuan HS, et al. Synergistic Inhibition of SARS-CoV-2 Replication Using Disulfiram/Ebselen and Remdesivir. ACS Pharmacology \& Translational Science 2021; 4: 898-907.

56 Sargsyan K, Lin C-C, Chen T, Grauffel C, Chen Y-P, Yang W-Z, et al. Multi-targeting of functional cysteines in multiple conserved SARS-CoV-2 domains by clinically safe Znejectors. Chemical Science 2020; 11: 9904-9.

57 Weglarz-Tomczak E, Tomczak JM, Talma M, Burda-Grabowska M, Giurg M, Brul S. Identification of ebselen and its analogues as potent covalent inhibitors of papain-like protease from SARS-CoV-2. Scientific Reports 2021; 11: 3640.

58 Sun LY, Chen C, Su J, Li JQ, Jiang Z, Gao H, et al. Ebsulfur and Ebselen as highly potent scaffolds for the development of potential SARS-CoV-2 antivirals. Bioorg Chem 2021; 112: 104889.

59 Galkin A, Kulakova L, Lim K, Chen CZ, Zheng W, Turko IV, et al. Structural basis for inactivation of Giardia lamblia carbamate kinase by disulfiram. J Biol Chem 2014; 289: 10502-9.

60 Paranjpe A, Zhang R, Ali-Osman F, Bobustuc GC, Srivenugopal KS. Disulfiram is a direct and potent inhibitor of human 06 -methylguanine-DNA methyltransferase (MGMT) in brain tumor cells and mouse brain and markedly increases the alkylating DNA damage. Carcinogenesis 2013; 35: 692-702.

61 Lin M-H, Moses DC, Hsieh C-H, Cheng S-C, Chen Y-H, Sun C-Y, et al. Disulfiram can inhibit MERS and SARS coronavirus papain-like proteases via different modes. Antiviral Research 2018; 150: 155-63.

62 Zandi K, Musall K, Oo A, Cao D, Liang B, Hassandarvish P, et al. Baicalein and Baicalin Inhibit SARS-CoV-2 RNA-Dependent-RNA Polymerase. Microorganisms 2021; 9. 
72063 Li Z, Li X, Huang Y-Y, Wu Y, Liu R, Zhou L, et al. Identify potent SARS-CoV-2 main 721 protease inhibitors via accelerated free energy perturbation-based virtual screening of 722 existing drugs. Proceedings of the National Academy of Sciences 2020; 117: 27381-7. 72364 Zhu W, Xu M, Chen CZ, Guo H, Shen M, Hu X, et al. Identification of SARS-CoV-2 3CL $724 \quad$ Protease Inhibitors by a Quantitative High-Throughput Screening. ACS Pharmacology \& 725 Translational Science 2020; 3: 1008-16.

72665 Kitamura N, Sacco MD, Ma C, Hu Y, Townsend JA, Meng X, et al. Expedited Approach 727 toward the Rational Design of Noncovalent SARS-CoV-2 Main Protease Inhibitors. $J$ $728 \quad$ Med Chem 2021. 